Illinois State University

ISU ReD: Research and eData

Theses and Dissertations

3-5-2019

\title{
Labeling Intimacy: Examining Attitude Differences About Romantic And Sexual Intimacy In Sexual And Asexual People
}

Alyssa N. Clark

Illinois State University, anclark117@gmail.com

Follow this and additional works at: https://ir.library.illinoisstate.edu/etd

Part of the Developmental Psychology Commons

\section{Recommended Citation}

Clark, Alyssa N., "Labeling Intimacy: Examining Attitude Differences About Romantic And Sexual Intimacy In Sexual And Asexual People" (2019). Theses and Dissertations. 1052.

https://ir.library.illinoisstate.edu/etd/1052

This Thesis is brought to you for free and open access by ISU ReD: Research and eData. It has been accepted for inclusion in Theses and Dissertations by an authorized administrator of ISU ReD: Research and eData. For more information, please contact ISUReD@ilstu.edu. 


\section{LABELING INTIMACY: EXAMINING ATTITUDE DIFFERENCES ABOUT ROMANTIC AND SEXUAL INTIMACY IN SEXUAL AND ASEXUAL PEOPLE}

\section{ALYSSA N. CLARK}

\section{Pages}

Although asexuality is a vastly understudied sexual orientation, some researchers have explored how asexual people navigate intimate relationships in order to see how and why they vary from cultural norms. There is a consistent lack of comparisons between sexual and asexual people, and no research has explored the frequencies of sexual attitude subgroups (i.e., sexpositive, sex-neutral, and sex-averse). Little quantitative data has been gathered on romantic partner label usage, as well as views on polyamory. The current study asked participants to complete the Experiences and Attitudes about Sexual and Intimate Behaviors questionnaire, the Engagement in Sexual Intimacy Attitude Scale, and the Romantic Partner Label questionnaire. These measures were developed for the current study to more accurately assess participant's attitudes and behaviors, as there was a lack of appropriate existing measures. My research questions focused on two major comparisons: sexual vs. asexual people, and sex-neutral vs. sexaverse asexual people. Results showed asexual people labeled behaviors as less sexual, were less likely to have participated in past behaviors, and were less likely to participate in the behaviors in the future. Asexual people were more likely to have a sex-neutral or sex-averse attitude, and used certain partner labels more or less. Also, asexual people had less relationship and sexual experience and were less likely to currently be in a romantic partner relationship. Further analyses indicated sex-averse asexual people were less willing to partake in physical behaviors in 
the future and used the partner label Boyfriend/girlfriend less. Additional results of these questions and a discussion of their possible implications for future research are considered.

KEYWORDS: asexuality; romantic relationships; partner labels; sex attitudes 
LABELING INTIMACY: EXAMINING ATTITUDE DIFFERENCES ABOUT ROMANTIC AND SEXUAL INTIMACY IN SEXUAL AND ASEXUAL PEOPLE

ALYSSA N. CLARK

A Thesis Submitted in Partial

Fulfillment of the Requirements for the Degree of

MASTER OF SCIENCE

Department of Psychology

ILLINOIS STATE UNIVERSITY

2019 
C 2019 Alyssa N. Clark 
LABELING INTIMACY: EXAMINING ATTITUDE DIFFERENCES ABOUT ROMANTIC AND SEXUAL INTIMACY IN SEXUAL AND ASEXUAL PEOPLE

ALYSSA N. CLARK

COMMITTEE MEMBERS:

Corinne Zimmerman, Chair

Marla Reese-Weber 


\section{ACKNOWLEDGMENTS}

Many thanks must be given to my thesis committee, for guiding me through this arduous process and helping me develop a coherent product. To Corinne, thank you for being the first person willing to engage with my ideas and encourage me to further explore asexual literature. You never doubted I would be able to handle the information and logistics of collecting data, and for that I am ever grateful. Your guidance kept me moving forward and allowed me to challenge not only myself, but the breadth of the current knowledge in the field. To Marla, without your brilliant integrations of definitions and theory I would not have been able accurately explain the intricacies between intimacy, romance, and sex. Your questions allowed me to included theories and explanations in my work that would have been detrimental to leave out. And to Byron, I cannot thank you enough for coming into my thesis with an open mind and meticulous questions. Being entrenched in a topic for a long time leaves you blind to what is left unclear to readers, and you always brought those aspects to light. Finally, I must thank my fellow graduate students, who listened time and time again to my theories and ideas and provided support for me along the way.

-A.N.C. 


\section{CONTENTS}

\section{Page}

ACKNOWLEDGMENTS

CONTENTS

ii

TABLES

FIGURES

CHAPTER I: INTRODUCTION 1

How is Asexuality Defined? 1

Asexuality and Intimate Relationship Experiences $\quad 5$

Intimate Relationships: Romantic vs. Sexual 5

$\begin{array}{ll}\text { Labeling Relationships } & 7\end{array}$

Differences in Romantic Relationship Desire and Maintenance $\quad 8$

$\begin{array}{ll}\text { Intimacy } & 10\end{array}$

Labeling Sexual and Romantic Acts $\quad 10$

Feelings About Engaging in Sexual Acts with a Partner 11

Non-Monogamous and Polyamorous Relationships 13

$\begin{array}{ll}\text { Summary } & 14\end{array}$

$\begin{array}{ll}\text { The Present Study } & 15\end{array}$

$\begin{array}{ll}\text { Research Questions } & 15\end{array}$

$\begin{array}{ll}\text { CHAPTER II: METHOD } & 18\end{array}$

$\begin{array}{ll}\text { Participants } & 18\end{array}$

$\begin{array}{ll}\text { Materials } & 19\end{array}$

$\begin{array}{ll}\text { Demographics. } & 19\end{array}$ 
Experiences and Attitudes about Physical Behaviors

The Physical Intimacy Experience Subscale

The Intimate Behavior Attitude Subscale

The Sexual Behavior Attitude Subscale

The Future Physical Intimacy Subscale

Engagement in Sexual Intimacy Attitude Scale

Romantic Partner Label Questionnaire.

Procedure

CHAPTER III: RESULTS

Sexual vs. Asexual Inferential Statistics

Asexual Subcategory Inferential Statistics

$\begin{array}{ll}\text { CHAPTER IV: DISCUSSION } & 38\end{array}$

$\begin{array}{ll}\text { Sexual vs. Asexual Comparisons } & 38\end{array}$

Sex-Neutral vs. Sex-Averse Asexual Comparisons 43

$\begin{array}{ll}\text { Strengths of the Present Study } & 47\end{array}$

$\begin{array}{ll}\text { Limitations and Future Directions } & 48\end{array}$

$\begin{array}{lr}\text { Implications and Conclusions } & 49\end{array}$

$\begin{array}{ll}\text { REFERENCES } & 51\end{array}$

APPENDIX A: DEMOGRAPHICS QUESTIONNAIRE 54

APPENDIX B: PHYSICAL INTIMACY EXPERIENCE SCALE 57

APPENDIX C: INTIMATE BEHAVIOR ATTITUDE SCALE 60

APPENDIX D: SEXUAL BEHAVIOR ATTITUDE SCALE 63

APPENDIX E: FUTURE PHYSICAL INTIMACY SCALE 66 

APPENDIX H: SOCIAL MEDIA RECRUITMENT TEXT TARGETING ASEXUAL

APPENDIX I: SOCIAL MEDIA RECRUITMENT TEXT FOR GENERAL RECRUITMENT 72 


\section{TABLES}

Table

Page

1. Means and Standard Deviations for Ratings of Physical Behaviors

(How Sexual and How Intimate) for Sexual and Asexual Participants

2. Means and Standard Deviations for Ratings of Physical Behaviors (Past Experience and Future Willingness) for Sexual and Asexual Participants

3. Means, Standard Deviations, and Range for Sex-Positive, Sex-Neutral, and Sex-Averse Sexual Participants on the Engagement in Intimacy Attitude Scale

4. Means, Standard Deviations, and Range for Sex-Positive, Sex-Neutral, and Sex-Averse Asexual Participants on the Engagement in Intimacy Attitude Scale

5. Percentage of Sexual and Asexual Partner Label Usage and Chi-Square Analyses

6. Percentage of Sex-Neutral and Sex-Averse Asexual Partner Label Usage and Chi-Square Analyses 


\section{FIGURES}

Figure

Page

1. A Comparison of Average Scores for Sexual and Asexual Participants across the Four Experiences and Attitudes about Sexual and Intimate Behaviors Sub-scales

2. A Comparison of Average Scores for Sex-Neutral and Sex-Averse Asexual Participants across the Experiences and Attitudes about Sexual and Intimate Behaviors Sub-Scales 


\section{CHAPTER I: INTRODUCTION}

Asexuality is a vastly understudied sexual orientation. When asexuality was first coined as a way to describe human sexuality, it was often pathologized or seen in an abnormal light (Van Houdehove, Enzlin, \& Gijs, 2017). Only recently has asexuality been perceived as a "positive way of being human" (Chasin, 2015, p.167). Despite the expanding literature, a definition of asexuality has not been agreed upon, and little is known about how asexual people navigate romantic relationships. Sexual intimacy is often a natural part of a romantic relationship (Willetts, Sprecher, \& Beck, 2004), and because asexual people lack sexual attraction they may navigate romantic relationships in a different manner. Asexual people may also label relationships in a non-normative way and differentiate between what actions or behaviors are inherently sexual. Non-monogamous or polyamorous relationships may also be perceived in a different fashion and may be seen as more appealing than the cultural norm. The goal of this literature review is to explore these nuances and to indicate gaps in the current literature that were used to guide the current research.

\section{How is Asexuality Defined?}

Within the last two decades asexuality has been defined in a myriad of ways by researchers, popular culture, and the internet. The definitions keep morphing because of an attempt to find a universal definition that captures the broadest number of people who identify as asexual. Previous research has tried to clarify the conceptualization of asexuality by focusing on self-identification (Brotto, Knudson, Inskip, Rhodes, \& Erskine, 2010; Carrigan, 2012; Gupta, 2017; Prause \& Graham, 2007), sexual behavior/desire (Prause \& Graham, 2007; Rothblum \& Brehony, 1993), and sexual attraction (Chasin, 2015; Scherrer, 2008; Van Houdenhove et al., 2017; Yule, Brotto, \& Gorzalla, 2015). Each proposed definition has its merits and faults, and the 
lack of general consensus among researchers highlights the term's fluidity and heterogeneous scope.

In many studies, self-identification was originally used to define asexuality as a way to circumnavigate the issue of recruiting participants without having a clear definition (e.g., Carrigan, 2012). These studies took advantage of the budding asexual community that at the time was predominantly online (Bogaert, 2015). The largest website dealing with asexuality is the Asexual Visibility and Education Network (AVEN), and researchers turned to this website for participants because of its widely recognized asexuality definition and convenience of eligible participants (Carrigan, 2011). AVEN's definition of asexuality is "someone who does not experience sexual attraction," and a number of studies have recruited samples predominantly from this website (Brotto et al., 2010; Carrigan, 2012; Robbins, Low, \& Query, 2016; Scherrer, 2008; Van Houdenhove, Gijs, T'Sjoen, \& Enzlin, 2015b). Using participants exclusively from AVEN limits a study's validity because AVEN's definition is not universally accepted within the asexual community (Carrigan, 2011). To explain, although Van Houdenhove et al. (2015b) found a majority of participants discovered asexuality through AVEN who accept its definition, Carrigan (2011) found participants who disagreed. Carrigan (2011) conducted a mixed-methods study with 130 self-identified asexual individuals, and found nuanced subgroups that do not match AVEN's definition. For example, participants identifying as asexual at times specified their asexuality as demi-sexual (only feeling sexual attraction after having a deep, emotional connection to someone), grey-A (falling somewhere between sexual and asexual), and $A$-fluid (asexuality that varies). Carrigan (2011) argues these subgroups of asexuality provide evidence that asexuality is an umbrella term. Yule et al. (2015) also point out that only using selfidentified asexual individuals is potentially problematic because the term is relatively new. Many 
people who are asexual may not be familiar with or identify with the term, and this leaves out a large faction of the population (Yule et al., 2015). Additionally, considering the apparent heterogeneity of the population that does identify with the word, researchers cannot be sure if they are actually studying the people they are trying to focus on (Yule et al., 2015). Thus, relying solely on self-identification is an inadequate way to define asexuality.

A second conceptualization of asexuality focuses on a lack of sexual behavior or desire, rather than on sexual attraction (Prause \& Graham, 2007; Rothblum \& Brehony, 1993). Prause and Graham (2007) tackled the pervasive idea that asexual people were lacking in something inherent, and this negative aspect separated them from the general population. They discussed how asexuality was pathologized as a lack of sexual behavior or desire and yet no evidence supported these claims. Prause and Graham (2007) conducted a study with over 1,000 participants, and the 40 participants who self-identified as asexual did not differ from other participants in sexual experience (i.e., behavior). Across all their measures, asexual people only had lower or absent sexual desire and arousability scores. They proposed that a more accurate definition included low, but not absent, sexual desire. And yet, defining asexuality as a lack of sexual desire may not be the most accurate definition. Additionally, Van Houdenhove, Gijs, T'Sjoen, and Enzlin (2015a) conducted a study delving into what asexual individuals described as being the most salient asexuality characteristic. Out of 526 self-identified asexual people, only 48.5\% agreed sexual behavior defines someone as asexual (Van Houdenhove et al., 2015a). As such, they concluded that sexual behavior is most likely a necessary but not sufficient factor when defining asexuality.

The third conceptualization of asexuality as a "lack of sexual attraction" has the most empirical support and has accumulated a growing consensus among researchers as the most 
accurate definition (Van Houdenhove et al., 2017). Bogaert (2004) first proposed a definition of asexuality as someone who had "never felt sexual attraction to anyone at all" (p.281). He derived this conceptualization from a study of over 18,000 participants, where about $1.05 \%$ responded to a question about sexual attraction as having never experienced it. He theorized this subgroup may differ from heterosexual, homosexual, and bisexual individuals, and should be classified as a separate orientation. This definition was not readily accepted by other researchers though, as they argued a general lack of sexual attraction, as opposed to a complete absence, captured more people who self-identified with the term and had similar experiences (Chasin, 2015; Scherrer, 2008; Yule et al., 2015).

Self-identification was not a strong enough argument to go against a more exclusionary definition, and both Yule et al. (2015) and Carrigan (2011) explored the idea of no vs. low sexual attraction. Yule et al. (2015) conducted a study of over 1,000 participants (316 self-identified asexual people) in order to create a simple questionnaire that delineated between sexual and asexual people. The scale they created included $93 \%$ of self-identifying asexual individuals and excluded $95 \%$ of other sexualities. Their scale delved into various aspects of sexual attraction and indicated a range of responses that can indicate someone is most likely asexual. Similarly, Carrigan (2011) also argued the definition of no sexual attraction excluded many self-identified asexual people. He suggested the definition of attraction was often subjective and may vary among individuals — especially among individuals who have never or very rarely experienced the feeling (Carrigan, 2011). Without providing a clear definition, some people may be inclined to say they had, in some form, experienced sexual attraction. As such, some asexual people may be excluded from studies if researchers focused on a definition of complete absence. Despite these conflicting views, researchers more often operationalize asexuality as a "lack of sexual 
attraction" as it adequately describes the experience of the most asexual people and has the most empirical support (Bogaert, 2015; Van Houdenhove et al., 2017). One of the goals of the present research was to further examine self-identification categories in a sample of asexual people, including comparisons between asexual and sexual people in order to further contextualize and understand possible similarities and differences.

\section{Asexuality and Intimate Relationship Experiences}

\section{Intimate Relationships: Romantic vs. Sexual}

Most intimate partner relationships are defined by the presence of sexual behaviors and attraction (Rothblum \& Brehony, 1993). But considering asexual people typically lack sexual attraction, are they likely to categorize intimate relationships differently? Previous research suggests they do, and that a clear line is drawn between romantic and sexual relationships, in that you can have one without the other, or both at the same time (Brotto et al., 2010). Asexual people are likely to separate romantic aspects from sexual aspects, and typically focus on romantic aspects when defining and classifying their relationships (Brotto et al., 2010). For example, Scherrer (2008) found asexual participants talked about romantic aspects (partnershipseeking, emotional bonding, non-sexual physical affection) when discussing their intimate relationships as opposed to focusing on the lack of sexual behavior. This classification style also seems to extend to how asexual people define their orientation, as they often label themselves with their romantic orientation instead of their sexual orientation (Brotto et al., 2010; Carrigan, 2011). The reasoning behind this apparent difference in self-identification is still unclear.

One theory proposed by Prause and Graham (2007) is that asexual people may have more negative experiences of sexual behaviors and do not wish to classify their partner relationships as such. A general aversion to sexual behavior may also prompt a romantic focus. To explain, 
Carrigan $(2011,2012)$ found subgroups of asexual people in relation to their sexual intimacy views, falling into groups of sex-positive, sex-neutral, or sex-averse. Sex-positive people had a healthy interest in or might enjoy sex (but experience no sexual drive or seek it out), sex-neutral people were indifferent and did not mind partaking in it, and sex-averse people were distressed and/or disgusted by it. Sex-neutral and sex-averse people were the two most commonly found subgroups, and may explain why asexual people classify their partner relationships based on romantic aspects (Carrigan, 2012).

Another possibility is that asexual people may find it confusing or cumbersome to describe their partner relationships through a sexual lens when they do not view the world through one (Brotto et al., 2010). For example, in a qualitative study of asexual women, Van Houdenhove et al. (2015b) found many women reported having thought everyone viewed the world as they did, with a disinterest in sexual intimacy. Participants indicated feeling confused as to why friends worried about sex, and they thought their friends were "making up" feelings about sexual attraction. It was not until these women were faced with repeated instances of others' sexual attractions before they understood they might have a different worldview. This non-sexual worldview seems to be pervasive as well, with multiple studies indicating asexual people not "understanding" sexual attraction as far back as adolescence (Bogaert, 2015; Brotto et al., 2010; Van Houdenhove et al., 2015b). As Bogaert (2015) explains, it is hard to recognize the absence of something, and this may be why asexual people classify partner relationships via romantic (i.e., present) aspects such as emotional bonding or non-sexual affection. Essentially, they are classifying their partner relationships based on what they $d o$ feel and experience, instead of what they do not feel or experience. 


\section{Labeling Relationships}

Asexual people might also use different terminology when labeling their romantic relationships. Specifically, they may take issue with common terms such as "boyfriend," "girlfriend," or other binary terms such as "single" or "taken" (Scherrer 2008, 2010b). Scherrer (2010b) poses these relationship terms are not appealing because they imply sexual intimacy. Asexual people may want to avoid implying sexual intimacy because their ideal relationship is often one with another asexual person, or one that is like a normal intimate relationship but without the sex (Van Houdenhove et al. 2015b). But as Carrigan (2015) points out, when sexual intimacy stops being the determination for relationships, things get "fuzzy." It is not uncommon for asexual people to report feeling confused about how to differentially describe their relationships between friends and intimate partners (Carrigan, 2015). Interestingly, asexual people insist they can tell the difference, even if they do not have the language to aptly describe it (Chasin, 2015). The lack of suitable vernacular to describe relationships is what Chasin (2015) argues is a salient issue within the community, and is driving attempts to create more applicable language. For example, the term "squish" refers to a non-romantic crush, and a non-romantic significant other of partner status (a queer-platonic relationship) is sometimes referred to as a "zucchini" (Chasin, 2015). The new vernacular stems from a younger age group, perhaps because they are familiar with the term asexuality from a younger age and are driven to create terms to describe their experiences (Chasin, 2015). At the same time, older generations have lived the majority of their lives without proper language and may feel they do not need new terms (Chasin, 2015). 


\section{Differences in Romantic Relationship Desire and Maintenance}

Considering the discourse over how asexual people define relationships, one has to wonder if asexual people differ from sexual people in whether or not they seek out intimate relationships. In a sample of 187 asexual people, Brotto et al. (2010) found one-third reported never having been in a traditionally defined intimate partner relationship, even into adulthood.

But is this pattern common for all asexual people, or does less experience reflect a lack of desire to be in a intimate relationship? Previous research indicates this pattern may not stem from a lack of desire, as asexual people do have partner relationship experience (Brotto et al. 2010; Dawson, McDonnel, \& Scott, 2016; Gupta et al., 2017). For example, in a qualitative study of 30 asexual people, Gupta et al. (2017) found that although only four participants were currently in partner relationships, two-thirds reported they wanted to find a romantic partner and be in a relationship. These findings are mirrored in Brotto et al. (2010), Carrigan (2012), Chasin (2015), and Scherrer (2010b) where a majority of asexual participants were not currently in partner relationships but reported having previous experience and wanting to be in one. Additionally, one may look at Brotto et al.'s (2010) results focusing on how although $30 \%$ of participants had no relationship experience, $70 \%$ did have experience. And yet, despite their apparent want of a partner relationship, many asexual people did not have one.

Very little research delves into why asexual people are unlikely to be in a partner relationship despite often desiring one. One explanation Scherrer (2010b) poses is that asexual people may feel a romantic relationship is an unattainable goal. Partner relationships may feel unattainable because asexual people are likely to fear their partner's reactions when navigating intimacy issues (Carrigan, 2012). As previously mentioned, some asexual people may not want to engage in sexual acts with a future partner (Carrigan, 2012), and because sexual intimacy is 
often a natural progression in healthy romantic relationships (Willetts et al., 2004), it is unlikely to be avoided without discussion. As such, asexual people may be wary navigating such a discussion, and more so if they are sex-averse and repulsed by engaging in sex (Carrigan, 2012). In contrast, navigating such a discussion may not be an issue for sex-neutral or sex-positive asexual people. To explain, some asexual people are willing to engage in unwanted, but consensual sex (Prause \& Graham, 2007). Dawson, McDonnell, and Scott (2016) reported that social pressure, wanting to please their partner, or wanting to hold the relationship together were among the reasons why asexual people participated in sex. Interestingly, Carrigan (2011) found more positive reasons, with references to wanting to let their partner know they loved them, wanting to have sex "for them" (not just because their partner wanted it), or wanting to have sex because they enjoyed sexual intimacy. What is less clear is whether sex-positive and sex-neutral asexual people are more or less likely to be in romantic relationships than sex-averse asexual people. If there is a difference, it may explain the variation in frequency of reported romantic relationships across studies, especially if studies had higher samples of sex-averse people.

Another reason asexual people may be hesitant to seek out or enter into a romantic relationship is because they fear having to "come out" to their future partners (Robbins et al., 2016). For asexual people, conversations about intimacy often lead to the asexual partner having to "come out" to explain why they do not want to engage in sexual intimacy (Robbins et al., 2016). These conversations may be daunting because asexuality is commonly pathologized by family, friends, and partners (Gupta et al., 2017; Robbins et al., 2016). For example, Gupta et al. (2017) reported instances where romantic partners told their asexual partner that they should seek treatment for their asexuality. Similarly, Robbins et al. (2016) reported reactions of disbelief, dismissal (their asexuality was "just a phase"), and that their asexuality was a 
proverbial "challenge" for their sexual partner to change their mind or prove them wrong. Granted, not every coming out experience resulted in a negative reaction (Robbins et al., 2016), but the positive coming out experiences occurred infrequently. As such, fear of coming out may be an extremely important barrier to asexual people seeking out romantic relationships. Further explorations into these nuanced experiences and worries would help clarify why or why not asexual people are unlikely to be in a romantic relationship.

\section{Intimacy}

\section{Labeling Sexual and Romantic Acts}

There is little research on how asexual people determine and label sexual and romantic acts such as holding hands, kissing, or making out. It is unclear how or why asexual people decide that a particular act is sexual or not, or whether or not sex-positive, sex-neutral, and sexaverse people label acts differently. What little we do know points towards physical affection that does not involve genitalia as wanted and non-sexual (Scherrer, 2010a). More specifically, acts such as kissing, cuddling, and caressing are often considered non-sexual and signs of physical affection that asexual people want in a relationship (Van Houdenhove et al., 2015b). Interestingly, labeling kissing, or even french-kissing as non-sexual goes against commonly, culturally agreed-upon norms (Scherrer, 2008; Willetts et al., 2004). Prause and Graham (2007) theorize asexual people label fewer acts as sexual because they are more likely to have higher sexual pleasure thresholds. To explain, with higher sexual pleasure thresholds, acts like kissing may become simply enjoyable in the moment and activate no inherent need to continue onto more intimate acts (Prause \& Graham, 2007).

Complicating the previous results, Scherrer (2008) noted there was large variation in the behaviors asexual participants reported as being romantic. One explanation for this heterogeneity 
is that sex-averse people might label more physical acts as sexual than sex-positive and sexneutral people. For example, some sex-averse people are sensitive to touch, and report not desiring any physical intimacy in their relationships (Van Houdenhove et al., 2015b). From this, their labeling of physical acts may be more in line with cultural norms because they may view any physical act as leading to something more sexual. Similarly, aromantic asexual people may also be more likely to classify physical actions such as kissing or cuddling as sexual. Scherrer (2008) and Carrigan (2011) define an aromantic person as someone who does not experience romantic attraction and does not seek out a romantic partner, and their ideal relationship is normally friendship-like. In contrast, a romantic person desires some level of physical affection and seeks out partnership (Scherrer, 2008). Although there is a clear distinction between aromantic and romantic asexual people (Carrigan, 2011), most studies include both as participants. With aromantic asexual people included in these analyses, it is possible the data are skewed because aromantic people may label more actions as sexual. One of the goals of the current study was to explore what acts asexual people label as sexual, and to examine differences in how sex-positive, sex-neutral, sex-averse, or aromantic people label such behaviors.

\section{Feelings About Engaging in Sexual Acts with a Partner}

Sexual intimacy between consenting partners in a relationship is often a positive emotional event (Willetts et al., 2004). In contrast, sexual experiences for asexual people have been found to be mostly negative (Prause \& Graham, 2007). Interestingly, Dawson et al. (2016) argues these negative experiences are no more extreme than the general population, even though viewing sexual experiences in a negative or neutral light is a trend in asexuality research (e.g., Carrigan, 2011). Brotto et al. (2010) theorizes these negative/neutral experiences may arise because asexual people separate the physical and emotional aspects of sexual intimacy. For 
example, asexual people tend to describe sex in technical terms or as "not registering" as an emotional act (Brotto et al., 2010; Carrigan, 2011). Similarly, when discussing their sexual experiences, many asexual participants described their experiences as "weird" or "void of feelings" (Van Houdenhove et al., 2015b). An emotional disconnect from feelings during sexual intimacy may be why asexual people commonly have indifferent or negative views about it. What is unclear though, is why asexual people experience this disconnection. Prause and Graham (2007) theorized that the emotional disconnection may have to do with sexual emotionality. They found asexual people had abnormally low or non-existent scores of both sexual arousal and excitability. With extremely low scores on these measures, it is not surprising asexual people often report not feeling emotions during sexual intimacy. And yet, what causes these low levels of arousal/excitability is still unknown. It would be beneficial to further explore neurochemical and biological possibilities as probable causes or predictors of low sexual arousal/excitability in asexual people.

Regardless of whether or not asexual people enjoy sexual intimacy with their partner, one must also ask how they feel about agreeing to partake in sex. Asexual people who are not sexaverse are likely indifferent to whether or not they have sex with their partners (Carrigan, 2011). To clarify, asexual people recognize that their (often) sexual partner enjoys and craves sexual intimacy and are often willing to partake in it when it is instigated by their partner (Van Houdenhove et al., 2015b). At the same time, since they themselves draw few emotions from the experience, they are less likely to instigate sexual intimacy (Van Houdenhove et al., 2015b). For those who are sex-averse though, they may only agree to sexual intimacy because they feel they have to in order to maintain their relationship (Van Houdenhove, et al. 2015b). A gap in the literature arises when it comes to sex-positive asexual people, in that there has been no 
exploration as to whether or not they are enthusiastic about engaging in sex or are likely to instigate sexual intimacy. Additionally, no study has compared sex-averse, sex-neutral, and sexpositive asexual people with respect to their opinions about agreeing to engage in sex.

\section{Non-Monogamous and Polyamorous Relationships}

Asexual people place a heavy emphasis on using emotional bonds to describe romantic relationships (Van Houdenhove et al., 2015b). To explain, asexual people reported that the key aspect of a romantic relationship was emotional bonds or connections with their partner, not sexual intimacy (Van Houdenhove et al., 2015b). In the same study, some asexual people went on to clarify that describing their relationships via sexual intimacy diminished the nature of their relationships. As mentioned above, asexual people often recognize their often (sexual) partner may want sexual intimacy and that they may not be able to satisfy their partner's needs (Scherrer, 2010b; Van Houdenhove et al., 2015b). Instead of letting the discrepancy in sexual drives strain their romantic relationship, asexual people may be open to their partner seeking out someone else for sexual intimacy as long as the sexual relationship did not become emotional (Brotto et al., 2010).

This potential openness to outside partners ties into monogamous vs. non-monogamous relationships. Although monogamy was often cited as an ideal relationship form, many asexual people were open to non-monogamies (Scherrer, 2010b). Van Houdenhove et al. (2015b) reported a similar trend, where asexual people were open to non-monogamies if their (sexual) partner craved that form of intimacy. Interestingly, one study found that monogamy was not always cited as a preferred relationship, unlike what may typically be expected (Scherrer, 2010b). Some participants noted monogamy often had a sexual connotation, and as such their ideal relationship involved a few people with strong romantic/emotional bonds, or even large 
open groups of more friendship-like relationships (Scherrer, 2010b). Although, Scherrer (2010b) did not gather information in order to make a distinction between aromantic-asexual and romantic-asexual participants, the prevalence of preferred non-monogamies may be attributed to how aromantic asexuals are less likely to seek out romantic partners. Additionally, no current study has compared asexual and sexual people's preferences or openness to non-monogamous or polyamorous relationship. The current study explored openness to polyamorous and nonmonogamous relationships and examined whether asexual participants' attitudes differed from sexual participants' attitudes.

\section{Summary}

The complexity that comes along with asexuality is aptly summed up by Van Houdenhove et al. (2015b), where they state "Asexuality is not a well-defined term or phenomenon" (p.262). Although progress has been made in defining asexuality, there are still considerable gaps in the literature surrounding how asexual people define intimate relationships and label behaviors as sexual. Research points toward clear distinctions between romantic and sexual relationships, focusing on emotional and non-sexual physical affection as being the most important factors (Van Houdenhove et al., 2015b). In contrast to more common cultural norms, asexual people tend to label typical sexual behaviors (such as kissing or cuddling) as non-sexual and preferred methods of physical affection (Scherrer, 2008). Non-monogamous and polyamorous relationships may also be viewed differently and may be seen as positive or wanted (Scherrer, 2010b). Although there are variations in how asexual people categorize these relationship aspects, such categorizations may relate to whether they have positive, neutral, or aversive reactions to sexual intimacy. As researchers we should delve into these variations and classifications in order to further understand the experiences and daily lives of asexual people, 
for the ways they and navigating relationships may deviate from cultural norms and may bring new and positive ways of experiencing relationships into light.

\section{The Present Study}

Due to the complexity of the asexuality research and the inherent lack of literature that compares asexual and sexual people, the current study includes two sets of research questions. The first set addresses questions that compare asexual and sexual participant responses, in an effort to examine not only if differences exist but also what those differences may be. The second set specifically addresses questions about asexual participants and focuses on three possible sub-categories of asexual people (sex-positive, sex-neutral, sex-averse) in order to further clarify what differences may exist among them.

\section{Research Questions}

\section{Asexual vs. Sexual}

Research Question 1: Are there differences in experiences with and feelings about physical behaviors within the context of a romantic relationship?

Research Question 1-1. Do sexual and asexual people have similar experiences with physical behaviors in past romantic relationships?

Research Question1-2. Are asexual people more likely to label physical behaviors as more intimate than sexual people do?

Research Question1-3. In the context of a romantic relationship, do sexual people label physical behaviors as more sexual than asexual people do?

Research Question1-4. Are asexual people less likely than sexual people to be willing to participate in physical behaviors in the future with a romantic partner(s)? 
Research Question 2: Considering attitudes towards sex, are sexual people more likely to self-identify as having sex-neutral or sex-positive attitudes whereas asexual people are more likely to self-identify as having sex-neutral or sex-averse attitudes?

Research Question 3: Do asexual people have less relationship experience and are they less likely to currently be in romantic relationships than sexual people?

Research Question 4-1: What labels do people use to describe their romantic partner relationships?

Research Question 4-2: Are asexual people less likely to use typical terms that imply sexual intimacy such as Boyfriend/girlfriend?

Research Question 5: Are asexual people more willing/open to polyamorous or open relationships than sexual people are?

\section{Asexual Subcategories Comparisons}

Research Question 6: What proportion of asexual people self-identify under the subcategories of sex-positive, sex-neutral, and sex-averse?

Research Question 7: Are there differences in experiences with and feelings about physical behaviors within the context of a romantic relationship?

Research Question 7-1: Have sex-averse asexual people participated in fewer physical behaviors in past romantic relationships?

Research Question 7-2: Do sex-positive, sex-neutral, and sex-averse asexual people label physical behaviors as intimate or non-intimate differently?

Research Question 7-3: Do sex-positive, sex-neutral, and sex-averse asexual people label physical behaviors as sexual or non-sexual differently? 
Research Question 7-4: Are sex-averse asexual people less likely to be willing to participate in sexual behaviors in the future with a romantic partner(s)?

Research Question 8: Do the potential sub-categories of asexual people vary with respect to (a) previous relationship experience, (b) current relationship status, and (c) what labels they use to describe their romantic relationships? 


\section{CHAPTER II: METHOD}

\section{Participants}

Six hundred and sixteen participants were recruited through a combination of websites (Tumblr, asexuality.org, asexuality.livejournal.com, Facebook) and Illinois State University's Computer Infrastructure and Support Services (CISS) email system. Six participants were excluded due to lack of consent. Ninety-six participants were further excluded for not responding to the sexual orientation question, as information about orientation was essential to address the research questions. Two participants did answer the sexual orientation question (with "I don't ... know" and "Confused"), but were excluded due to being unable to categorize their sexual orientation. Five hundred and twelve participants were retained for the current study's analyses.

Four hundred and three participants self-identified as sexual; 75.7\% as heterosexual, $5.2 \%$ as gay/lesbian, $12.4 \%$ as bisexual, $4.7 \%$ as pansexual, and $2 \%$ as other. Only one participant self-identified as aromantic. Sexual participants were on average 29.03 years old (SD $=13.94$; range $=18-77)$. Sexual participants were $59.1 \%$ female $(40.4 \%$ male, $0.5 \%$ other $)$, and $57.3 \%$ identified as women, $38.2 \%$ as men, $1.5 \%$ as transgender, $1.2 \%$ as non-binary, $1.2 \%$ as genderfluid, and $0.5 \%$ as other. With respect to race/ethnicity, $84.9 \%$ identified as White/European American, 3.7\% as Black/African American, 4\% as Hispanic/Latinx, 3\% as Asian/Pacific Islander, $0.2 \%$ as Native American, 3.7\% as Multi-racial/Multi-ethnic, and 0.5\% as other.

One hundred and nine participants identified as asexual. With respect to subcategories provided, $61.5 \%$ identified as asexual, $17.4 \%$ as grey-A, $19.3 \%$ as demi-sexual, and $1.8 \%$ as other. Twenty-six participants identified as aromantic. Asexual participants were on average 27.66 years old $(S D=9.28$; range $=18-62)$. Asexual participants were $69.7 \%$ female $(26.6 \%$ 
male, $0.9 \%$ other, $2.8 \%$ preferred not to answer) and $58.7 \%$ identified as women, $21.1 \%$ as men, $0.9 \%$ as transgender, $11.9 \%$ as non-binary, $3.7 \%$ as genderfluid, and $3.7 \%$ as agender/genderless. With respect to race/ethnicity, $80.7 \%$ identified as White/European American, $3.7 \%$ as Black/African American, 6.4\% as Hispanic/Latinx, 3.7\% as Asian/Pacific Islander, 0.9\% as Native American, 3.7\% as Multi-ethnic/multi-racial, and $0.9 \%$ as other.

\section{Materials}

Data were collected through a questionnaire, comprised of several sub-scales, demographics, and open-ended questions.

Demographics. Demographic questions included age, race/ethnicity, sex, gender, sexual orientation, romantic orientation, and willingness to engage in a polyamorous relationship (see Appendix A). Additional questions were asked about the participant's preferred sexual orientation for themselves and a romantic partner. Open-ended responses included questions about previous and current sexual and romantic relationship experiences, with various explanation prompts. Additionally, information about age of first romantic and first sexual experiences was collected.

Experiences and Attitudes about Physical Behaviors. Within the context of an intimate partner relationship, participants' attitudes about how sexual and intimate physical behaviors are, as well as their past and possible future engagement in various physical behaviors were obtained through four scales comprised of a list of 22 physical behaviors. These behaviors were the same for each scale and ranged from conventionally non-sexual (e.g., hand holding, cuddling), to conventionally sexual (e.g., genital/genital contact; see Appendices B through E). These scales were created specifically for this study, as there is currently a lack of comprehensive measures, 
and the behaviors were chosen in an effort to compile every possible close physical action a person might perform with a romantic partner.

The Physical Intimacy Experience Subscale assesses a person's previous experience with physically intimate behaviors and is measured on a 5 -point Likert scale $(1=$ Never, $2=$ Seldom, 3 = Sometimes, $4=$ Often, $5=A$ lot $)$. A higher score indicates more previous experience with physically intimate behavior.

The Intimate Behavior Attitude Subscale assesses how intimate a person perceives a behavior to be and is measured on a 5 -point Likert scale $(1=$ Not intimate to $5=$ Very intimate $)$. A higher score indicates a stronger likelihood of viewing physical behaviors as intimate.

The Sexual Behavior Attitude Subscale assesses how sexual or non-sexual a person believes a behavior to be and is measured on a 5 -point Likert scale $(1=$ Not sexual to $5=$ Very sexual). A higher score indicates a stronger likelihood to view physical behaviors as sexual.

The Future Physical Intimacy Subscale assesses how likely a person is to engage in physically intimate behaviors in the future, and is measured on a 5-point Likert scale ( $1=$ Not at all likely, to $5=$ Extremely likely). A higher score indicates more willingness to participate in physically intimate behaviors in the future.

The four subscales were presented with the two scales closest in meaning being placed the farthest apart. That is, the scale assessing past sexual behavior was presented first, followed by the two scales asking about intimate and sexual behavior attitudes, finishing with the scale assessing future willingness. This order was chosen to dissuade participants from assuming the scales are asking the same questions and responding the same across the board. Moreover, instructions emphasized the ways in which the four subscales were different. Scores for these subscales were calculated by averaging a participant's score across all items. 
Engagement in Sexual Intimacy Attitude Scale. To measure attitudes about engaging in sexual intimacy, six dichotomous antonym pairs were rated on a scale of 0 to 100 , with the lower bound consisting of the more aversive word in each pair. Antonym pairs consisted of negative/positive, disgusted/pleased, uninterested/interested, not aroused/aroused, averse/not averse, and unwilling/willing (see Appendix F). These pairings and a sliding scale rating were created and chosen for this study in order to attain an aggregated picture in which participants may be divided into three groups: sex-averse, sex-neutral, and sex-positive. A follow-up question directly asking participants' attitude toward engaging in sex (positive, neutral, averse, or none of these apply to me) was given after this section.

Romantic Partner Label Questionnaire. This questionnaire consists of a comprehensive list of 18 items that people may use to refer to a romantic partner and were listed in order of least (i.e., Crush) to most (i.e., Husband/wife) perceived commitment (see Appendix G). A checked box beside an item denoted that a person would use that item in reference to a romantic partner; an unchecked box denoted the item would not be used. Items were not linked; participants could check as many or as few of the items they preferred and had the option to write in other responses for the last item. Box totals were tallied and total use scores across participants were compared (e.g., participant A selected more labels than participant B). Individual items were also tallied across all participants and were compared to totals of other items (e.g. Significant Other was selected as a label by more participants than the label Lover). This questionnaire was created specifically for this study.

\section{Procedure}

The questionnaire was administered through an online survey using Qualtrics. First, forum-based websites were identified and the administrators of each website (e.g., 
asexuality.org, asexuality.livejournal.com) were contacted and to ask for permission to advertise the research study. After permission was granted, a brief description and link to the survey was posted on each website. Considering the differences in targeted samples, the brief survey description varied slightly based on where it was posted. The same description was used for asexuality.org, asexuality.livejournal.com, and Tumblr (see Appendix H). Similarly, a slightly different description was used for Facebook and CISS (see Appendix I).

After navigating to the survey link, participants were asked to provide consent and verify that they were at least 18 years old. Once they provided consent and verified their age, participants continued to the rest of the survey. Participants completed four scales (Appendices B-E), the Engagement in Sexual Intimacy Attitude Scale (Appendix F), and the Romantic Partner Label Questionnaire (Appendix G). After this, participants were asked basic demographic and open-ended questions (Appendix A). Upon completion of the survey, participants were thanked for their time, offered a debriefing statement, and given the opportunity to provide an email address if they wished to be entered into a gift card raffle. Participant emails were stored separately from their surveys, and no other identifying information was collected. 


\section{CHAPTER III: RESULTS}

The purpose of the present study was to address the research questions outlined in Chapter I. The first set of questions addresses comparisons between sexual and asexual participants, and the second set of questions addresses comparisons between subcategories of asexual participants (i.e., sex-neutral and sex-averse asexual participants).

\section{Sexual vs. Asexual Inferential Statistics}

In order to address whether age (i.e., lack of life experience) was a possible confounding factor, an independent samples $t$-test comparing sexual $(M=29.03$ years; $S D=13.94)$ and asexual $(M=27.66$ years; $S D=9.28)$ participants' ages was conducted. The age difference between groups was not significant, $t(506)=0.96, p=.34$.

For Research Questions 1-1 through 1-4, Table 1 displays the means and standard deviations for participants' sexual and intimacy behavior attitudes for each behavior individually. Table 2 displays the means and standard deviations for participants' past experience with each of the 22 behaviors and their future willingness to engage in them. Average scores across the 22 items were computed in order to compare participant groups for research questions 1-1 through 1-4 (see Figure 1.)

For Research Question 1-1, an independent samples $t$-test was conducted to explore how past experience with physical behaviors may differ between sexual and asexual participants (see Figure 1). There was a significant difference between sexual and asexual people, $t(510)=13.23$, $p \leq .001, d=1.47$. Sexual participants were more likely to have participated in various physical behaviors in the past $(M=3.32, S D=0.95)$ than asexual participants $(M=2.00, S D=0.85)$.

Research Question 1-2 compared how intimate sexual and asexual participants define the 22 physical behaviors. In this case, there was not a significant difference between the groups, 
$t(149.85)=1.58, p=.117, d=0.17$. Behaviors were rated as intimate in similar ways for both sexual $(M=3.92, S D=0.62)$ and asexual participants $(M=3.80, S D=0.75)$.

To examine Research Question 1-3, an independent samples $t$-test was conducted to examine sexual and asexual participants' labeling of physical behaviors as sexual. There was a significant difference in the average ratings between sexual and asexual people, $t(509)=3.60, p$ $\leq .001, d=0.42$, in that sexual participants rated the set of physical behaviors as more sexual ( $M$ $=3.66, S D=0.53)$ than asexual participants $(M=3.46, S D=0.41)$.

Research Question 1-4 addressed whether sexual and asexual participants differ in future willingness to participate in various physical behaviors. There was a significant difference in the average ratings of the 22 behaviors between sexual and asexual people, $t(143.33)=14.80, p \leq$ $.001, d=1.72$. Sexual people were more willing to participate in various physical behaviors in the future $(M=4.25, S D=0.74)$ than asexual people $(M=2.77, S D=0.97)$. 
Table 1

Means and Standard Deviations for Ratings of Physical Behaviors (How Sexual and How Intimate) for Sexual and Asexual Participants

\begin{tabular}{|c|c|c|c|c|}
\hline & Sexua & ating & Intima & Rating \\
\hline & Sexual & Asexual & Sexual & Asexual \\
\hline & $M(S D)$ & $M(S D)$ & $M(S D)$ & $M(S D)$ \\
\hline Holding hands & $1.56(.89)$ & $1.23(.54)$ & $2.84(1.06)$ & $2.49(1.01)$ \\
\hline Hugging & $1.65(.96)$ & $1.25(.57)$ & $2.84(1.15)$ & $2.55(.94)$ \\
\hline Cuddling & $2.40(1.00)$ & $1.77(.84)$ & $3.69(.95)$ & $3.49(1.10)$ \\
\hline Caressing & $2.90(1.07)$ & $2.58(.96)$ & $3.81(.95)$ & $3.68(1.00)$ \\
\hline Massaging above clothes & $2.56(1.05)$ & $2.17(1.00)$ & $3.14(1.05)$ & $3.05(1.11)$ \\
\hline Massaging under clothes & $3.56(.98)$ & $3.20(1.12)$ & $3.99(1.00)$ & $3.86(1.06)$ \\
\hline Fondling above clothes & $3.63(.95)$ & $3.70(.95)$ & $3.78(.99)$ & $3.90(1.07)$ \\
\hline Fondling under clothes & $4.16(.85)$ & $4.18(.76)$ & $4.26(.97)$ & $4.21(1.02)$ \\
\hline Sharing a bed & $2.79(1.25)$ & $1.85(.97)$ & $3.88(1.11)$ & $3.18(1.18)$ \\
\hline Kissing on the lips & $3.03(1.08)$ & $2.51(.99)$ & $3.88(.98)$ & $3.50(1.03)$ \\
\hline Kissing above the neck & $3.25(1.10)$ & $2.69(1.07)$ & $3.86(.99)$ & $3.34(1.12)$ \\
\hline $\begin{array}{l}\text { Kissing below the neck } \\
\text { (excluding genitals) }\end{array}$ & $3.97(.93)$ & $3.53(.93)$ & $4.21(.95)$ & $3.97(1.12)$ \\
\hline French-kissing & $3.83(1.01)$ & $3.86(.99)$ & $4.16(.97)$ & $4.01(1.19)$ \\
\hline Making out & $3.92(.96)$ & $3.80(1.03)$ & $4.18(.93)$ & $4.04(1.20)$ \\
\hline Humping & $4.23(.93)$ & $4.45(.69)$ & $3.81(1.24)$ & $4.12(1.26)$ \\
\hline Foreplay & $4.57(.71)$ & $4.53(.76)$ & $4.35(.94)$ & $4.31(.99)$ \\
\hline $\begin{array}{l}\text { Bodily contact/touching } \\
\text { nipples/breasts }\end{array}$ & $4.66(.64)$ & $4.51(.65)$ & $4.43(.92)$ & $4.35(1.05)$ \\
\hline $\begin{array}{l}\text { Bodily contact/touching } \\
\text { genitals }\end{array}$ & $4.83(.55)$ & $4.94(.28)$ & $4.56(.88)$ & $4.52(1.13)$ \\
\hline Genital touching orally & $4.86(.58)$ & $4.93(.43)$ & $4.59(.90)$ & $4.49(1.22)$ \\
\hline $\begin{array}{l}\text { Genital/genital contact } \\
\text { (including intercourse) }\end{array}$ & $4.90(.52)$ & $4.95(.25)$ & $4.69(.83)$ & $4.59(1.11)$ \\
\hline $\begin{array}{l}\text { Anal touching (including } \\
\text { orally) }\end{array}$ & $4.61(1.05)$ & $4.84(.69)$ & $4.05(1.52)$ & $4.43(1.31)$ \\
\hline $\begin{array}{l}\text { Anal/genital contact } \\
\text { (including intercourse) }\end{array}$ & $4.63(1.04)$ & $4.88(.59)$ & $4.10(1.50)$ & $4.44(1.30)$ \\
\hline
\end{tabular}


Table 2

Means and Standard Deviations for Ratings of Physical Behaviors (Past Experience and Future Willingness) for Sexual and Asexual Participants

\begin{tabular}{|c|c|c|c|c|}
\hline & \multicolumn{2}{|c|}{ Past Experience } & \multicolumn{2}{|c|}{ Future Willingness } \\
\hline & Sexual & Asexual & Sexual & Asexual \\
\hline & $M(S D)$ & $M(S D)$ & $M(S D)$ & $M(S D)$ \\
\hline Holding hands & $3.85(1.14)$ & $2.93(1.30)$ & $4.78(.69)$ & $4.31(1.84)$ \\
\hline Hugging & $4.11(.98)$ & $3.35(1.32)$ & $4.85(.59)$ & $4.50(1.01)$ \\
\hline Cuddling & $4.03(1.14)$ & $2.82(1.51)$ & $4.83(.60)$ & $4.12(1.31)$ \\
\hline Caressing & $3.46(1.25)$ & $2.25(1.40)$ & $4.56(.91)$ & $3.56(1.42)$ \\
\hline Massaging above clothes & $3.01(1.24)$ & $2.00(1.09)$ & $4.28(1.11)$ & $3.36(1.46)$ \\
\hline Massaging under clothes & $2.89(1.31)$ & $1.72(1.01)$ & $4.19(1.18)$ & $2.91(1.49)$ \\
\hline Fondling above clothes & $3.10(1.26)$ & $1.70(.95)$ & $4.19(1.17)$ & $2.42(1.36)$ \\
\hline Fondling under clothes & $3.29(1.31)$ & $1.63(.94)$ & $4.25(1.16)$ & $2.28(1.34)$ \\
\hline Sharing a bed & $3.76(1.46)$ & $2.69(1.46)$ & $4.65(.88)$ & $3.82(1.37)$ \\
\hline Kissing on the lips & $4.30(1.17)$ & $2.66(1.51)$ & $4.82(.64)$ & $3.69(1.45)$ \\
\hline Kissing above the neck & $3.98(1.25)$ & $2.40(1.43)$ & $4.70(.82)$ & $3.45(1.49)$ \\
\hline $\begin{array}{l}\text { Kissing below the neck } \\
\text { (excluding genitals) }\end{array}$ & $3.23(1.37)$ & $1.73(1.04)$ & $4.44(1.06)$ & $2.67(1.43)$ \\
\hline French-kissing & $3.42(1.36)$ & $2.00(1.27)$ & $4.33(1.11)$ & $2.56(1.52)$ \\
\hline Making out & $3.65(1.30)$ & $2.01(1.32)$ & $4.54(.92)$ & $2.56(1.51)$ \\
\hline Humping & $2.64(1.32)$ & $1.46(.89)$ & $3.65(1.43)$ & $1.87(1.20)$ \\
\hline Foreplay & $3.36(1.40)$ & $1.73(1.08)$ & $4.34(1.20)$ & $2.17(1.31)$ \\
\hline $\begin{array}{l}\text { Bodily contact/touching } \\
\text { nipples/breasts }\end{array}$ & $3.59(1.35)$ & $1.87(1.17)$ & $4.49(1.06)$ & $2.25(1.39)$ \\
\hline $\begin{array}{l}\text { Bodily contact/touching } \\
\text { genitals }\end{array}$ & $3.51(1.37)$ & $1.63(.98)$ & $4.50(1.04)$ & $2.00(1.29)$ \\
\hline Genital touching orally & $3.12(1.42)$ & $1.50(.90)$ & $4.29(1.24)$ & $1.76(1.18)$ \\
\hline $\begin{array}{l}\text { Genital/genital contact } \\
\text { (including intercourse) }\end{array}$ & $3.41(1.48)$ & $1.59(1.07)$ & $4.47(1.11)$ & $1.92(1.32)$ \\
\hline $\begin{array}{l}\text { Anal touching (including } \\
\text { orally) }\end{array}$ & $1.68(1.10)$ & $1.16(.49)$ & $2.30(1.51)$ & $1.39(.80)$ \\
\hline $\begin{array}{l}\text { Anal/genital contact } \\
\text { (including intercourse) }\end{array}$ & $1.68(1.14)$ & $1.13(.43)$ & $2.34(1.54)$ & $1.41(.88)$ \\
\hline
\end{tabular}


5

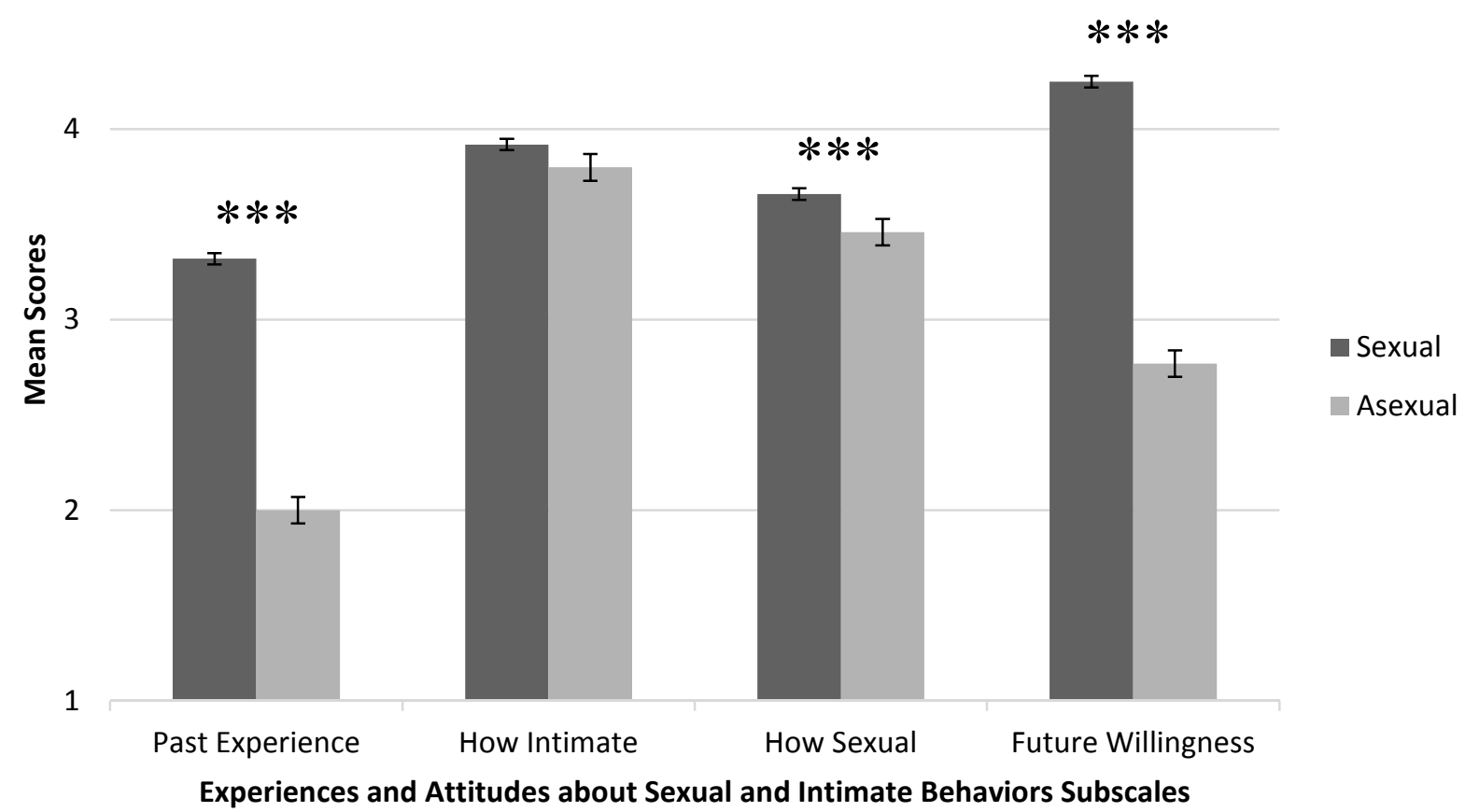

Figure 1. A comparison of average scores for sexual and asexual participants across the four Experiences and Attitudes about Sexual and Intimate Behaviors sub-scales. Note: ${ }^{*} p<.05,{ }^{* *} p$ $<.01, * * * p<.001$ 
In order to address Research Questions 2 and 6, it was necessary to classify participants with respect to their sexual attitude. Scores for the antonym pairs on the Engagement in Sexual Intimacy Attitude Scale were related to the question that directly asked participants to self-identify into the categories of positive, neutral, or averse (see Appendix F). Because of the sufficient overlap across these six items and the direct question (see Table 3 for sexual participants and Table 4 for asexual participants), responses to the direct question were used to group participants into sex-positive, sex-neutral, and sex-averse categories. These labels were used in all subsequent analyses, and excluded 14 participants who responded, "none of these labels apply to me."

Table 3

Means, Standard Deviations, and Range for Sex-Positive, Sex-Neutral, and Sex-Averse Sexual Participants on the Engagement in Intimacy Attitude Scale

\begin{tabular}{|c|c|c|c|c|c|c|}
\hline & \multicolumn{6}{|c|}{ Sex-Attitude } \\
\hline & \multicolumn{2}{|c|}{$\begin{array}{c}\text { Sex-Positive } \\
\quad(n=319)\end{array}$} & \multicolumn{2}{|c|}{$\begin{array}{c}\text { Sex-Neutral } \\
(n=59)\end{array}$} & \multicolumn{2}{|c|}{$\begin{array}{c}\text { Sex-Averse } \\
\quad(n=10)\end{array}$} \\
\hline & $M(S D)$ & Range & $M(S D)$ & Range & $M(S D)$ & Range \\
\hline Negative/Positive & $90.22(12.60)$ & $20-100$ & $60.67(20.80)$ & $5-100$ & $28.70(25.00)$ & $0-85$ \\
\hline Disgusted/Pleased & $86.97(19.93)$ & $0-100$ & $62.93(22.90)$ & $10-100$ & $38.90(25.87)$ & $0-85$ \\
\hline Uninterested/Interested & $87.27(18.72)$ & $0-100$ & $57.30(23.40)$ & $1-100$ & $26.90(29.76)$ & $0-83$ \\
\hline Not Aroused/Aroused & $84.02(20.19)$ & $0-100$ & $62.88(24.20)$ & $1-100$ & $44.10(37.36)$ & $0-90$ \\
\hline Averse/Not Averse & $82.84(24.54)$ & $0-100$ & $58.64(23.64)$ & $0-100$ & $25.10(23.38)$ & $0-53$ \\
\hline Unwilling/Willing & $87.81(19.98)$ & $0-100$ & $60.07(23.68)$ & $2-100$ & $23.40(18.83)$ & $0-50$ \\
\hline
\end{tabular}


Table 4

Means, Standard Deviations, and Range for Sex-Positive, Sex-Neutral, and Sex-Averse Asexual Participants on the Engagement in Intimacy Attitude Scale

\begin{tabular}{lcccccc}
\hline & \multicolumn{5}{c}{ Sex-Attitude } \\
\cline { 2 - 7 } & \multicolumn{2}{c}{$\begin{array}{c}\text { Sex-Positive } \\
(n=6)\end{array}$} & $\begin{array}{c}\text { Sex-Neutral } \\
(n=41)\end{array}$ & $\begin{array}{c}\text { Sex-Averse } \\
(n=54)\end{array}$ \\
& $M(S D)$ & Range & $M(S D)$ & Range & $M(S D)$ & Range \\
\hline Negative/Positive & $65.33(35.09)$ & $1-92$ & $48.46(20.89)$ & $0-85$ & $20.09(20.36)$ & $0-83$ \\
Disgusted/Pleased & $66.33(33.68)$ & $1-92$ & $47.41(18.99)$ & $0-100$ & $17.65(17.16)$ & $0-60$ \\
Uninterested/Interested & $52.83(38.61)$ & $1-90$ & $25.88(23.62)$ & $0-80$ & $4.65(7.62)$ & $0-30$ \\
Not Aroused/Aroused & $61.67(31.30)$ & $1-85$ & $27.61(24.56)$ & $0-80$ & $9.52(16.02)$ & $0-70$ \\
Averse/Not Averse & $71.33(36.56)$ & $1-100$ & $51.05(25.93)$ & $0-100$ & $10.17(14.87)$ & $0-60$ \\
Unwilling/Willing & $62.17(35.03)$ & $1-100$ & $49.37(24.61)$ & $0-91$ & $11.63(18.76)$ & $0-75$ \\
\hline
\end{tabular}

For Research Question 2, a chi-square analysis was conducted to examine the frequencies in which sexual and asexual participants self-identify with three intimacy attitude sub-categories (sex-positive, sex-neutral, sex-averse). Sexual orientation and intimacy attitudes were significantly related, $\chi^{2}(2, N=496)=257.44, p<.001$. The proportions of sexual participants who identified as sex-positive, sex-neutral, and sex-averse were $.82, .15$, and .03, respectively. Conversely, the proportions of asexual participants who identified as sex-positive, sex-neutral, and sex-averse were $.06, .41$, and .53 , respectively.

Research Question 3 addressed whether asexual people differ from sexual people with respect to past and current relationship experience. The majority of sexual participants (88\%) reported having past romantic relationship experience, compared to about half $(54 \%)$ of the 
asexual participants, $\chi^{2}(1, N=512)=63.93, p<.001$. Eighty percent of sexual participants had previous sexual experience, whereas only $43 \%$ of asexual participants had previous sexual experience, $\chi^{2}(1, N=512)=58.70, p<.001$. There was also a significant relation between sexual orientation and current relationship status, $\chi^{2}(1,512)=49.33, p<.001$. The percentages of sexual and asexual participants who were currently in a relationship were $61 \%$ and $23 \%$, respectively.

Research Question 4-1 examined the labels people use for their romantic partners. The total frequency counts for all participants are depicted in Table 5. As can be seen, very few labels were used by more than half of the participants. Best friend, Boyfriend/girlfriend, Significant Other, and Partner were among the most commonly used terms, whereas Crush, Person, Better Half, Soulmate, Datemate, and Life Partner were among the most infrequently used. Write-in responses included Friend and Queer-Platonic Partner from asexual participants.

Research Question 4-2 addressed whether asexual people are less likely to use relationship labels that typically imply sexual intimacy. Seven relationship labels were compared with chi-square tests to determine whether asexual participants were less likely to use each term. The seven relationship labels were Crush, Boyfriend/girlfriend, Lover, Romantic Partner, Spouse, Fiancé, and Husband/wife (see Table 5). The chi-squares for Crush, Boyfriend/girlfriend, Romantic Partner, Spouse, Fiancé, and Husband/wife, were not significant (all $p$ 's $>.05)$. In contrast, sexual people were more likely to use the label Lover compared to asexual people. Follow-up analysis comparing additional partner labels indicated a significant difference for the labels Other Half, Better Half, Soulmate, and Partner. For every label except Partner, asexual participants were less likely to use the label (see Table 5). 
Research Question 5 examined whether asexual people are more open to polyamorous relationships than sexual people. Responses for openness to polyamory/polyamorous relationships were grouped into three sub-categories (yes, maybe/no preference, and no/not looking for a partner). There was no significant relation between sexuality and openness to polyamory, $\chi^{2}(2, \mathrm{~N}=512)=3.29, p=.193$. Proportions of sexual people who responded with "yes", "maybe/no preference", and "no/not looking for a partner" were .11, .22, and .67, respectively. Asexual people responded with "yes", "maybe/no preference", and "no/not looking for a partner" $.17, .25$, and .59 , respectively. 
Table 5

Percentage of Sexual and Asexual Partner Label Usage and Chi-Square Analyses

\begin{tabular}{|c|c|c|c|c|}
\hline \multirow[b]{2}{*}{ Partner Label } & \multicolumn{3}{|c|}{ Percentage } & \multirow[b]{2}{*}{$\chi^{2}$} \\
\hline & Sexual & Asexual & Total & \\
\hline Crush & 20 & 15 & 19 & $\chi^{2}(1, N=512)=1.38, p=.241$ \\
\hline Best Friend & 44 & 41 & 44 & $\chi^{2}(1, N=512)=.29, p=.590$ \\
\hline Boyfriend/girlfriend & 67 & 65 & 67 & $\chi^{2}(1, N=512)=.17, p=.678$ \\
\hline Date & 32 & 26 & 31 & $\chi^{2}(1, N=512)=1.61, p=.204$ \\
\hline Datemate & 3 & 4 & 3 & $\chi^{2}(1, N=512)=.14, p=.713$ \\
\hline Person & 18 & 25 & 20 & $\chi^{2}(1, N=512)=2.23, p=.136$ \\
\hline Other half $*$ & 26 & 16 & 24 & $\chi^{2}(1, N=512)=4.96, p=.026$ \\
\hline Better half $* *$ & 24 & 12 & 21 & $\chi^{2}(1, N=512)=6.99, p=.008$ \\
\hline Significant other & 54 & 53 & 54 & $\chi^{2}(1, N=512)=.04, p=.833$ \\
\hline Companion & 28 & 27 & 28 & $\chi^{2}(1, N=512)=.21, p=.728$ \\
\hline Lover $* * *$ & 36 & 14 & 31 & $\chi^{2}(1, N=512)=18.97, p \leq .001$ \\
\hline Soulmate * & 23 & 13 & 21 & $\chi^{2}(1, N=512)=5.66, p=.017$ \\
\hline Partner $* * *$ & 44 & 63 & 48 & $\chi^{2}(1, N=512)=12.25, p \leq .001$ \\
\hline Life partner & 22 & 16 & 21 & $\chi^{2}(1, N=512)=2.36, p=.125$ \\
\hline Romantic partner & 28 & 25 & 27 & $\chi^{2}(1, N=512)=.40, p=.529$ \\
\hline Fiancé & 20 & 28 & 22 & $\chi^{2}(1, N=512)=3.00, p=.084$ \\
\hline Spouse & 26 & 28 & 27 & $\chi^{2}(1, N=512)=.07, p=.798$ \\
\hline Husband/Wife & 39 & 34 & 38 & $\chi^{2}(1, N=512)=.75, p=.388$ \\
\hline Other & 6 & 6 & 6 & $\chi^{2}(1, N=512)=.00, p=.985$ \\
\hline Friend $* * *$ & 1 & 6 & 2 & $\chi^{2}(1, N=512)=12.03, p=.001$ \\
\hline Pet names & 1 & 0 & 1 & $\chi^{2}(1, N=512)=.816, p=.366$ \\
\hline $\mathrm{QPP}^{+} * * *$ & 0 & 4 & 1 & $\chi^{2}(1, N=512)=14.91, p \leq .001$ \\
\hline
\end{tabular}

Note: ${ }^{+} \mathrm{QPP}=$ Queer-Platonic Partner; ${ }^{*} p<.05, * * p<.01, * * * p<.001$ 


\section{Asexual Subcategory Inferential Statistics}

Research Question 6 addressed the frequencies at which asexual people self-identified with the intimacy sub-categories (sex-positive, sex-neutral, sex-averse). As noted previously, the proportions of asexual participants who identified as sex-positive, sex-neutral, and sex-averse were $.06, .41$, and .54 , respectively. Sex-positive asexual people were excluded from further analyses, as with only six participants, this group was too small for analysis purposes. Follow-up analyses were conducted to examine proportions at which asexuals who identify as aromantic self-identify with the three sub-categories. Aromantic asexual participants $(n=26)$ identified as sex-positive $(n=1 ; 4 \%)$, sex-neutral $(n=10 ; 35 \%)$, and sex-averse $(n=15 ; 58 \%)$.

Research Questions 7-1 to 7-4 involve comparisons between sex-neutral and sex-averse participants on the four subscales of the Experiences and Attitudes about Sexual and Intimate Behaviors. As with Research Questions 1-1 to 1-4, an average was computed across the 22 items in order to make comparisons (see Figure 2).

Research Question 7-1 questioned whether sex-averse asexual people had fewer past experiences with physical behaviors than sex-neutral asexual people. Interestingly, there was not a significant difference in past experience between sex-averse and sex-neutral asexual participants, $t(93)=.51, p=.614, d=0.11$. Sex-neutral participants were as likely to have participated in various physical behaviors in the past $(M=2.00, S D=.87)$ as sex-averse asexual participants $(M=1.91, S D=.76)$.

Research Question 7-2 addressed how sex-neutral and sex-averse asexual participants define the 22 physical behaviors with respect to how intimate they are. Again, there was not a significant difference between the groups $t(93)=-.19, p=.851, d=0.04$. Sex-neutral asexual 
people $(M=3.75, S D=.74)$ and sex-averse asexual people $(M=3.78, S D=.80)$ rated behaviors as similarly intimate.

5

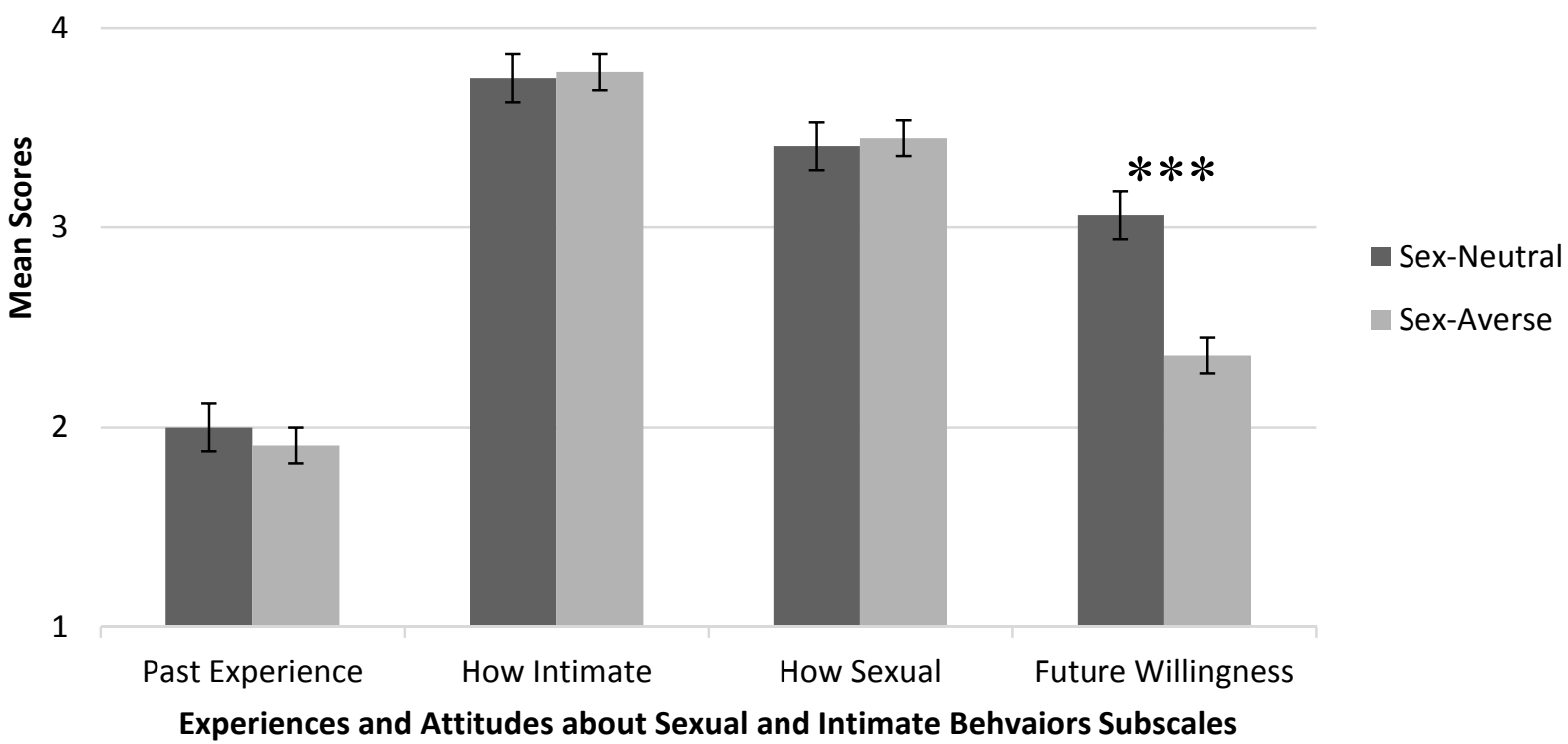

Figure 2. A comparison of average scores for sex-neutral and sex-averse asexual participants across the Experiences and Attitudes about Sexual and Intimate Behaviors sub-scales.

Note: $* p<.05, * * p<.01, * * * p<.001$

Research Question 7-3 examined sex-neutral and sex-averse asexual participants' labeling of physical behaviors as sexual. There was no significant difference between sex-neutral asexual people $(M=3.41, S D=.32)$ and sex-averse asexual people $(M=3.45, S D=.46), t(92)=-.55, p$ $=.587, d=0.10$. 
Research Question 7-4 considered whether sex-averse asexual people were less likely to want to participate in various physical behaviors in the future when compared to sex-neutral asexual people. In this case, there was a significant difference in the average ratings between sex-averse and sex-neutral participants. Sex-averse asexual people were less willing to participate in various physical behaviors in the future $(M=2.36, S D=.74)$ than sex-neutral asexual people $(M=3.06, S D=.92), t(93)=4.16, p \leq .001, d=0.84$.

Research Question 8 consisted of four related questions addressing possible difference between sex-neutral and sex-averse asexual people with respect to (a) past/current relationship status, (b) past sexual experience, and (c) romantic partner label use. With respect to past romantic relationship experience, sex attitude was not related to past relationship experience, $\chi^{2}$ $(1, N=95)=.79, p=.373$. Forty-six percent of sex-neutral asexual participants had past relationship experience, similar to $56 \%$ of sex-averse asexual participants. Similarly, with respect to current romantic relationship status, sex attitude was not related to current relationship status, $\chi^{2}(1, N=95)=.10, p=.748$. Twenty percent of sex-neutral asexual people were currently in a relationship, similar to $22 \%$ of sex-averse asexual people. Considering past sexual experience, sex attitude was not related to previous experience, $\chi^{2}(1, N=95)=1.78, p=.182$. The percentages of sex-neutral and sex-averse asexual people who had previous sexual experience were $49 \%$ and $35 \%$, respectively. Follow-up analyses indicated the majority of aromantic asexual participants did not have previous relationship experience (69\%), were not currently in a relationship (96\%), and did not have past sexual experience (73\%).

The labels that sex-neutral and sex-averse asexual people use for their romantic partners are depicted in Table 6 with percentage of each group who use the label. Similar to Research Question 4-2, seven relationship labels were compared with chi-square tests to examine whether 
sex-neutral or sex-averse asexual participants were equally as likely to use each term. Again, the seven terms were Crush, Boyfriend/girlfriend, Lover, Romantic Partner, Spouse, Fiancé, and Husband/wife (see Table 6). The only label that was used with a different frequency was Boyfriend/girlfriend, with sex-neutral participants more likely to use this label relative to sexaverse participants. 
Table 6

Percentage of Sex-Neutral and Sex-Averse Asexual Partner Label Usage and Chi-Square Analyses

\begin{tabular}{|c|c|c|c|c|}
\hline \multirow[b]{2}{*}{ Partner Label } & \multicolumn{3}{|c|}{ Percentage } & \multirow[b]{2}{*}{$\chi^{2}$} \\
\hline & Sex-Neutral & Sex-Averse & Total & \\
\hline Crush & 10 & 13 & 12 & $\chi^{2}(1, N=95)=.23, p=.629$ \\
\hline Best Friend & 42 & 44 & 43 & $\chi^{2}(1, N=95)=.08, p=.771$ \\
\hline Boy/girlfriend $* *$ & 81 & 52 & 64 & $\chi^{2}(1, N=95)=8.32, p=.004$ \\
\hline Date & 29 & 26 & 27 & $\chi^{2}(1, N=95)=.13, p=.717$ \\
\hline Datemate & 5 & 4 & 4 & $\chi^{2}(1, N=95)=.08, p=.778$ \\
\hline Person & 20 & 28 & 24 & $\chi^{2}(1, N=95)=.87, p=.352$ \\
\hline Other half & 15 & 15 & 15 & $\chi^{2}(1, N=95)=.001, p=.980$ \\
\hline Better half & 17 & 9 & 13 & $\chi^{2}(1, N=95)=1.29, p=.256$ \\
\hline Significant other & 63 & 50 & 56 & $\chi^{2}(1, N=95)=1.70, p=.192$ \\
\hline Companion & 32 & 22 & 26 & $\chi^{2}(1, N=95)=1.08, p=.298$ \\
\hline Lover & 15 & 13 & 14 & $\chi^{2}(1, N=95)=.06, p=.814$ \\
\hline Soulmate & 12 & 13 & 13 & $\chi^{2}(1, N=95)=.01, p=.911$ \\
\hline Partner & 61 & 65 & 63 & $\chi^{2}(1, N=95)=.15, p=.701$ \\
\hline Life partner & 20 & 13 & 16 & $\chi^{2}(1, N=95)=.75, p=.386$ \\
\hline Romantic partner & 34 & 19 & 25 & $\chi^{2}(1, N=95)=3.02, p=.083$ \\
\hline Fiancé & 39 & 22 & 30 & $\chi^{2}(1, N=95)=3.17, p=.075$ \\
\hline Spouse & 34 & 24 & 28 & $\chi^{2}(1, N=95)=1.16, p=.281$ \\
\hline Husband/Wife & 42 & 33 & 37 & $\chi^{2}(1, N=95)=.66, p=.416$ \\
\hline Other & 5 & 6 & 5 & $\chi^{2}(1, N=95)=.02, p=.884$ \\
\hline Friend & 5 & 7 & 6 & $\chi^{2}(1, N=95)=.25, p=.616$ \\
\hline $\mathrm{QPP}^{+}$ & 0 & 7 & 4 & $\chi^{2}(1, N=95)=3.17, p=.075$ \\
\hline
\end{tabular}

Note: ${ }^{+} Q P P=$ Queer-Platonic Partner; ${ }^{*} p<.05,{ }^{* *} p<.01, * * * p<.001$ 


\section{CHAPTER IV: DISCUSSION}

In the current research I assessed attitudes and behaviors associated with romantic partner relationships, focusing on physical behaviors, romantic partner labels, and openness to polyamorous relationships to further understand the nuances of intimate partner relationships. My research questions were split into two comparison categories in order to explore differences between sexual and asexual groups while also considering possible within-group differences in the asexual group (sex-neutral vs. sex-averse asexual people).

\section{Sexual vs. Asexual Comparisons}

Research Question 1 was split into four sub-sections, which addressed the question of how people label physical behaviors within the context of a romantic relationship along with their past experiences and future willingness to engage in these behaviors. My first sub-question asked whether sexual and asexual people have similar past experience with physical behaviors, and my data indicated asexual people were less likely to have participated in the 22 physical behaviors. In accordance with Carrigan's $(2011,2012)$ qualitative reports that asexual people often have negative experiences surrounding sex, it is not surprising that they have less experience than a sexual person. An asexual person may be more reluctant to try engaging in sex and related physical behaviors, regardless of their feelings for their partner, and if they have negative or neutral feelings while engaging in sex or other related physical behaviors, it is possible they only tried them once. It is also possible that affectionate behaviors were the threshold of tolerable physical intimacy, and while asexual people participated in them, more stereotypical foreplay or sexual behaviors were too aversive to try. Either possibility would result in lower overall experience than sexual people, who typically take enjoyment from sex and are more willing to partake in it again. There was no significant difference in age between sexual 
and asexual participants, and participants were on average in their late 20 's, which implies that it is not a lack of life experience that explains why asexual people have lower levels of sexual experience.

The second and third sub-research questions addressed attitudes and perceptions about the intimacy and sexuality of various physical behaviors. Interestingly, I did not find support for the idea that asexual people were more likely to label physical behaviors as intimate than sexual people. Both groups labeled them similarly, but these results may be explained when one considers how the same behaviors were labeled as sexual. To clarify, although all participants agreed upon the intimate nature of these behaviors, asexual people labeled behaviors as less sexual. This finding may relate to Prause and Graham's (2007) evidence that asexual people experience less sexual desire and excitability. If an asexual person is not excited by physical actions, they may not view those actions as sexual because their bodies are not responding to them in a sexually conventional way. When specific physical behaviors were examined, I found asexual people labeled behaviors such as kissing, cuddling, and caressing as less sexual. This pattern supports the findings by Sherrer (2008) in which asexual people qualitatively mentioned themes of not seeing these specific behaviors as sexual. What is important to note though, is that Sherrer's findings did not compare asexual to sexual people, and her sample may not actually deviate from a sexual norm. In contrast, my results compare sexual and asexual people, and may indicate that asexual people do deviate from a sexual norm.

The fourth sub-question asked whether asexual people were less willing to partake in physical behaviors in the future with a romantic partner. I found evidence that asexual participants were less willing to partake in these physical behaviors in future. Importantly, my research provides preliminary evidence to support the notion that asexuality is not a transitory 
sexual identity, but that it is a stable underlying influence on a person's sexual behavior. To explain, the majority of sexuality research typically considers only whether or not a person has ever engaged in sexual intercourse, and fails to consider their future willingness or intentions. The ramifications of this oversight are that someone who partakes in sex daily and someone who has only done it once are lumped under the same category as having past sexual experience. Have they sexual experience? Yes. But the issue is that my research indicates that asexual people may be part of the latter group: they have tried it once, but do not want to do it again.

When considering attitudes toward engaging in sex, I found that sexual people were more likely to identify as sex-positive and sex-neutral, whereas asexual people were more likely to identify as sex-neutral and sex-averse. Originally, Carrigan (2011) hypothesized that asexual people could be divided into these three categories, and did not consider sexual people may also identify with these categories. My study provides support that both sexual and asexual people not only have some variability in their attitudes, but also that their attitudes tend to fall on opposite ends of the spectrum. This pattern addresses the pervasive notion that asexual people view sex as physically aversive, and may explain why some asexual people have less experience and are less willing to partake in it in the future. But there was an equally representative subset of asexual individuals who had neutral feelings about sex and were more likely to consider such behaviors in a romantic relationship, relative to those who are sex-averse. Additionally, although Carrigan (2011) explained the theoretical possibility of sex-positive asexual people, I did not find conclusive evidence that this category exists. Similarly, there were very few sex-averse sexual people, which may hint at biological or neurochemical differences in bodily responses to sexual engagement that differentiates sexual and asexual people. 
With respect to my third research question about current and past relationship experience and sexual experience, I found that regardless of age, asexual people were less likely to have had previous romantic relationship experience and were less likely to currently be in one.

Additionally, asexual people were less likely to have previous sexual experience. These findings are in direct contrast with Brotto et al. (2010) who found a majority of asexual participants (70\%) at least had relationship experience. Almost half of my asexual participants (46\%) did not have any previous relationship experience. This finding may be explained by the large number of aromantic asexual people in this sample. Aromantic asexual people may not have romantic relationship experience because they do not want to, not because they cannot find a suitable partner or are afraid to try. Interestingly, I found non-aromantic asexual people had less experience than sexual people overall, above and beyond the influence of aromantic asexual individuals. Granted, no other study reported the romantic orientations of their participants, and future considerations into differences between the experiences of aromantic asexuals and romantic asexuals must be considered. Additionally, no other study compared asexual and sexual people. It is possible that even if the majority of a group of asexual people have had previous relationship experience, when they are compared to a sexual group, their percentage may fall below what is considered typical. Essentially, there is far more variability within those who identify as asexual than past research has indicated.

Research Question 4 explored what labels people use to describe their romantic partners, and surprisingly, I found that only the terms Boyfriend/girlfriend and Significant Other were used more than by $50 \%$ of participants. The most commonly used labels were Boyfriend/girlfriend, Significant Other, and Partner. These findings provide a preliminary basis 
for romantic partner label usage across varying sexualities and indicate possible trends in the overall population.

When comparing sexual and asexual people, in contrast to previous evidence (Sherrer, $2008,2010 \mathrm{~b}$ ) asexual participants were not less likely to use typical terms that implied sexual intimacy, except for the term Lover. This may suggest the other terms do not imply sexual intimacy, or that asexual people do not view them as sexual. One may argue their lack of usage stems from viewing them as sexual terms, similar to Sherrer's $(2008,2010 \mathrm{~b})$ original argument for why Boyfriend/girlfriend, Single, or Taken are disliked. Interestingly, asexual participants did use the term Partner more than sexual people, which may indicate asexual people may view this term as more neutral in regards to sexual intimacy. Granted, the current research only explored possible usage, and further clarification for the reasoning behind the usage or the lack of usage is needed.

Although previous research has indicated asexual people may be open to nonmonogamies or polyamorous relationships (Sherrer, 2010b), I did not find evidence that they are more open to these types of relationships than sexual people. It is possible that the lack of differences between sexual and asexual people may stem from the reasoning behind why someone may or may not engage in an open or polyamorous relationship. To explain, asexual people often explained their willingness to partake in a polyamorous relationship because they recognize they may not satisfy their partner's sexual needs (Sherrer, 2010b). Sexual people may reason differently, and may focus on love for more than one person or emotional-bonding. Although, it could equally be possible that sexual people may not match their partner's sexual needs, and as such may be willing to engage in a polyamorous relationship. Future research 
should continue to examine people's willingness to engage in these relationships while obtaining reasoning behind their specific choice.

\section{Sex-Neutral vs. Sex-Averse Asexual Comparisons}

As previously mentioned, the majority of asexual people self-identified as sex-neutral $(40.6 \%)$ or sex-averse $(53.5 \%)$, with a very small minority who self identified as sex-positive. These results provide support for the trend in qualitative research that indicates asexual people often describe their feelings toward sexual intercourse in a neutral way, or find sexual intercourse and related physical behaviors as aversive. A novel finding of my study is the ratios at which asexual people self-identify into these groups. I found that asexual people identified with both labels in similar proportions. It is unclear whether this pattern is unique to the specific sample, or if it is representative of the population. Additionally, it is also unclear why sex-neutral and sex-averse asexual people differ in their attitudes toward sex. To explain, one could argue that their attitudes are a matter of personal choice or preference. This may be the explanation, but sex-averse asexual people often describe their adverse reactions as physical reactions. For example, sex-averse asexual people often physically feel disgusted by sexual intercourse, and at times, benign acts such as kissing. This physical reaction can be analogized to a person's dislike of certain foods. A person may not eat a certain food because they experience a physically unpleasant reaction, and this reaction often has nothing to do with whether the person wants to like the food. It is a matter of physical reaction, not personal preference. Regardless, exploration into the differences between sex-neutral and sex-averse asexual people could further clarify the nuances of asexuality and sexual reactions, and whether the basis for such differences are biological or psychological. 
Research Question 7-1 asks whether sex-averse asexual people have participated in fewer physical behaviors in past romantic relationships and surprisingly sex-neutral and sex-averse people did not differ in this aspect. These findings may be rooted in the hypersexual nature of relationships and society (Przybylo, 2016). Although sex-averse people may find sex unpleasant, the social pressure they feel to either please a partner or engage in societal norms may be strong enough to override the aversive nature of sex. As Van Houdenhove et al. (2015b) argued, sexaverse asexual people may only partake in sex to maintain their relationships. Multiple studies provide evidence that asexual people face adverse reactions to their asexuality (Gupta, 2017; Robbins et al., 2016; Van Houdenhove et al., 2015b), and their relationships have not lasted when they did not conform to sexual norms (Haefner, 2012). As such, even sex-averse asexual people may partake in sex to maintain their romantic relationships. Although, no research has been conducted thus far to explore both sexual attitudes among those who are neutral or averse and the reasons for partaking in sex despite either lack of physical arousal or feelings of aversion.

Research Questions 7-2 and 7-3 are thematically linked, as they consider how sexual or how intimate various behaviors are perceived to be. Interestingly, sex-neutral and sex-averse asexual people labeled these behaviors similarly. Previously, I had theorized that sex-averse asexual people may label behaviors more similar to sexual people, considering sex was often an aversive experience (Prause \& Graham, 2007). It is surprising then, that not only did sex-averse asexual people label behaviors as less sexual than sexual people, but also were similar to sexneutral asexual people. One may argue this finding arises from a possible disconnect between an asexual person's perceptions of and attitudes towards sexual interactions. To explain, asexual people in general may perceive certain actions as sexual or non-sexual, but these perceptions 
may not be affected by their personal attitude. Someone may have an aversive attitude (as opposed to a neutral attitude), but their perceptions are not influenced by their feelings. An analogous example would be that while someone may dislike the color blue, they will still agree that the color is, in fact, blue. Essentially, a disconnect between feelings and perceptions is made, and examining the lack of discrepancy between sex-neutral and sex-averse asexual people would be beneficial to understanding their internal mechanisms.

Future willingness to participate in sex was vastly different for sexual and asexual people, and Research Question 7-4 addressed this comparison for the two asexual sub-categories. I found that sex-averse asexual people were less willing to participate in sexual behaviors in the future with a romantic partner relative to those who identify as sex-neutral. As mentioned above, no study has examined an asexual person's future willingness to engage in physical behaviors, and my results highlight the need to consider this aspect of what it means to be asexual. Sex-neutral and sex-averse asexual people have similar past experience, but there is something fundamentally different about a sex-averse asexual person's experiences, attitudes, or perceptions that leads to a significantly lower willingness to participate in sex in the future, and further exploration is needed to help clarify and understand their experiences.

My final research question explored any possible differences between sex-neutral and sex-averse individuals in romantic partner label usage and romantic relationship experience. There were no differences between the asexual sub-categories with previous relationship experience, current relationship status, or previous sexual experience. This result reinforces the idea that differences between sex-neutral and sex-averse asexual people do not seem to arise from an inherent difference in experience. That is, although both sub-categories have participated in similar types of physical behaviors and have similar amounts of past relationship experience, 
sex-averse asexual people still have lower future willingness to engage in physical behaviors in the context of a romantic relationship. One could argue sex-averse asexual people have lower future willingness because they lack experience, and theoretically could not know they are averse to sex if they never tried it, but my results do not support this notion. Also, the argument of "you haven't tried it yet" is often used to discriminate or erase an asexual person's identity and feelings (e.g., Carrigan, 2012). Why do people often assume sex must be tried for someone to form an opinion on it? By analogy, there are many activities (e.g., touching a hot stove) that most people would agree are harmful or they dislike even if they have not done it themselves. Similarly, asexual people often have negative opinions of sex, regardless of experience. This aversion appears to be stronger for sex-averse asexual people, as reflected in their lower future willingness scores. Without clarification of the reasoning behind their lower willingness, one cannot argue for a lack of experience without excluding the very people we are trying to understand.

Finally, the two asexual sub-categories used similar romantic partner labels except for the term Boyfriend/girlfriend. These findings support Sherrer (2008, 2010b), where asexual people took issue with this term because it implies sexual intimacy. In the current study, only sex-averse asexual people used this term less, which may imply that Sherrer's sample included a larger number of sex-averse people. Conversely, it is possible the current sample of sex-averse people may dislike the term for a different reason. Future exploration into the qualitative reasoning behind the term's lack of use with sex-averse people will help broaden our understanding of relationship terminology and help us better understand sex-averse asexual people. 


\section{Strengths of the Present Study}

In addition to the expansion of understanding provided to my research questions, it is important to note the strengths of the current study and how it provides a comprehensive expansion of both asexual and romantic relationship research. First, my asexual sample size is relatively large compared to some studies, and I specifically targeted my recruitment toward asexual organizations. What this means is that I have a reasonably large sample of asexual participants who are aware of their own asexuality, and may have had more time to reflect upon their feelings about romantic and sexual intimacy. Additionally, my asexual sample was not primarily recruited from AVEN; at least half of my asexual participants were gathered from other websites. As mentioned in Chapter I, exclusive recruitment from AVEN can be problematic because of AVEN's definition of asexuality (Carrigan, 2011) and so having a more diverse range of participants from various websites is beneficial.

Second, the creation of a comprehensive questionnaire about physical behaviors is the first of its kind, as far as I am aware. The creation of this survey instrument allowed an in-depth exploration into experiences with and attitudes about behaviors in a nuanced way that previous research has lacked. Further, my questionnaire not only examined past behavior, but also considered future willingness to engage in behaviors. Future willingness is, or should be, a crucial aspect of asexuality research, and this questionnaire will hopefully be beneficial to future research. Third, this study can be used to provide preliminary evidence of romantic partner label usage across people of differing sexualities, and further may be used as a baseline when discussing possible trends in vernacular among adults in the US.

Finally, the current study is one of few that actively compare sexual to asexual people, and provides clarification to similarities and differences between the two groups. Additionally, 
no other study has collected information on self-identification into the sex-positive, sex-neutral, and sex-averse categories, or compared results for asexual participants within these subcategories. Allowing participants to identify their attitudes toward sex may help to explain some of the conflicting findings in existing asexuality research.

\section{Limitations and Future Directions}

There are several areas upon which the current study's design may be improved for future research. To begin, although letting participants self-identify as asexual is beneficial, it is also a limitation as some asexual people may be unaware of or hesitant to identify with the term (e.g., Yule et al., 2015). Asexual people may also define asexuality differently, and without using a scale (such as the Asexuality Identification Scale; Yule et al., 2015) it is unclear how many selfidentified sexual participants may actually be asexual, or vice versa. Similarly, participant recruitment was spread across several websites, all participants were recruited online. Relying solely in online recruitment means my sample may differ from the population of asexual individuals. That is, my sample of asexual participants may be more attuned to their asexuality, are familiar with the term asexuality, and/or know others identifying with the term (in person or via social media) that may have influenced their perceptions of what it means to be "asexual." Future research would benefit from recruiting people from offline communities, and could be used as a better representation of asexual population statistics.

Second, neither the Experiences and Attitudes about Physical Behaviors subscales nor the Romantic Partner Label Questionnaire items were pilot-tested. Therefore, it is possible that items on both measures may be missing (e.g., other sexual or intimate behaviors; other romantic partner labels) or would benefit from clarification in instructions. With the Experiences and Attitude subscales, some behaviors (or behavior terminology) may be outdated and may benefit 
from being collapsed or combined into one category for a simplified questionnaire. In the future, both questionnaires should be re-examined and re-administered to understand the reliability and validity in order to strengthen their possible uses within similar bodies of research.

In general, although the current study begins to explore a wide breadth of intimacy attitudes and issues among sexual and asexual people, future research is needed to continue building upon the current results. Although asexual people view certain physical behaviors as less sexual, it is unclear why they do. Prause and Graham (2007) provide evidence that asexual people physically experience less sexual arousal and excitement, and a direct comparison between mental attitudes and physical reactions may be key in understanding their experiences. Similarly, there must be something fundamentally different between sexual and asexual people that led to asexual people more likely being sex-neutral or sex-averse. Although there were sexual people who were sex-neutral and sex-averse, it is unclear whether they are similar to or different from asexual people, and further exploration could help discover possible nuances that have not previously been considered. Finally, while the current study considered romantic partner labels, relationship labels were not examined. Including relationship labels in addition to romantic partner labels would help clarify Sherrer's $(2008,2010 \mathrm{~b})$ qualitative findings that asexual people are less likely to use terms such as "single" or "taken."

\section{Implications and Conclusions}

This study was created to explore both sexual and asexual people's attitudes, perceptions, and behaviors about various aspects of romantic partner relationships and physical intimacy. As discussed above, given previous findings that indicate (a) asexual people may be hesitant or view physical behaviors differently, (b) can be identified as sex-positive, sex-neutral, or sex-averse, (c) may be less likely to use certain romantic partner labels, and (d) may be more open to 
polyamory or polyamorous relationships, my goal was to further examine these areas in an effort to gain a more nuanced understand asexual people's experiences and how they compare to a sexual norm.

As such, my preliminary evidence not only highlights how sexual and asexual people vary in the previously mentioned areas, but also provides a baseline for categorization of all sexualities into a trichotomy of sex attitudes in addition to a baseline for romantic partner label usage. And while asexual differed across measures from a sexual norm, their experiences were no less valid or indicative of a lack of anything aside from sexual attraction. Moving forward, researchers must continue to question a purely sexual conceptualization of romantic relationships and physical intimacy, and must consider asexual experiences as ones that, while different, simply provide a uniquely enriched way of experiencing these behaviors. Future research should continue to examine asexual attitudes and behaviors in order to better understand human sexuality, and the lived experiences of a group that is often ignored or forgotten. 


\section{REFERENCES}

Asexuality Visibility and Education Network (2017). Overview. Retrieved from http://www.asexuality.org/home/overview.html

Bogaert, A. F. (2004). Asexuality: Prevalence and associated factors in a national probability sample. Journal of Sex Research, 41(3), 279-287. doi:10.1080/00224490409552235

Bogaert, A. F. (2015). Asexuality: What it is and why it matters. Journal of Sex Research, 52(4), 362-379. doi:10.1080/00224499.2015.1015713

Brotto, L. A., Knudson, G., Inskip, J., Rhodes, K., \& Erskine, Y. (2010). Asexuality: A mixedmethods approach. Archives of Sexual Behavior, 39(3), 599-618. doi:10.1007/s10508008-9434-x

Carrigan, M. (2011). There's more to life than sex? Difference and commonality within the asexual community. Sexualities, 14(4), 462-478. doi:10.1177/1363460711406462

Carrigan, M. A. (2012). "How do you know you don't like it if you haven't tried it?" Asexual agency and the sexual assumption. In T. G. Morrison, M. A. Morrison, M. A. Carrigan, \& D. T. McDermott (Eds.), Sexual Minority Research in the New Millennium (pp. 3-20). UK: Nova Science Publishers.

Chasin, C. D. (2015). Making sense in and of the asexual community: Navigating relationships and identities in a context of resistance. Journal of Community \& Applied Social Psychology, 25(2), 167-180. doi:10.1002/casp.2203

Dawson, M., McDonnell, L., \& Scott, S. (2016). Negotiating the boundaries of intimacy: The personal lives of asexual people. The Sociological Review, 64(2), 349-365. doi:10.1111/1467-954X.12362 
Gupta, K. (2017). 'And now I'm just different, but there's nothing actually wrong with me': Asexual marginalization and resistance. Journal of Homosexuality, 64(8), 991-1013. doi: $10.1080 / 00918369.2016 .1236590$

Haefner, C. (2012). Asexual scripts: A grounded theory inquiry into the intrapsychic scripts asexuals use to negotiate romantic relationships. Dissertation Abstracts International: Section B. Sciences and Engineering, 72(8-B), 5025.

Prause, N., \& Graham, C. A. (2007). Asexuality: Classification and characterization. Archives of Sexual Behavior, 36(3), 341-356. doi:10.1007/s10508-006-9142-3

Przybylo, E. (2016). Introducing asexuality, unthinking sex. In N. L. Fischer \& S. Seidman (3rd Eds.) Introducing the New Sexuality Studies (pp. 181-191) NY, US: Routledge Taylor \& Francis Group Publishers

Robbins, N. K., Low, K. G., \& Query, A. N. (2016) A qualitative exploration of the 'coming out' process for asexual individuals. Archives of Sexual Behavior, 45(3), 751-760. doi:10.1007/s10508-015-0561-x

Rothblum, E. D., \& Brehony, K. A. (1993). Boston marriages: Romantic but asexual relationships among contemporary lesbians. Amherst, MA, US: The University of Massachusetts Press.

Scherrer, K. S. (2008). Coming to an asexual identity: Negotiating identity, negotiating desire. Sexualities, 11(5), 621-641. doi:10.1177/1363460708094269

Scherrer, K. S. (2010a) What asexuality contributes to the same-sex marriage discussion. Journal of Gay \& Lesbian Social Services: The Quarterly Journal of Community \& Clinical Practice,22(1-2), 56-73. doi:10.1080/10538720903332255 
Scherrer, K. S. (2010b) What does asexuality have to do with polyamory? In M. Baker, \& D. Langdridge (Eds.), Understanding Non-Monogamies (pp. 154-159). London: Routledge.

Van Houdenhove, E., Gijs, L, T'Sjoen, G., \& Enzlin, P. (2015a). Asexuality: A multidimensional approach. Journal of Sex Research, 52(6), 669-678. doi:10.1080/00224499.2014.898015

Van Houdenhove, E., Gijs, L, T'Sjoen, G., \& Enzlin, P. (2015b). Stories about asexuality: A qualitative study on asexual women. Journal of Sex \& Marital Therapy, 41(3), 262-281. doi:10.1080/0092623X.2014.889053

Van Houdenhove, E., Enzlin, P., \& Gijs, L. (2017). A positive approach toward asexuality: Some first steps, but still a long way to go. Archives of Sexual Behavior, 46(3), 647-651. doi:10.1007/s10508-016-0921-1

Willetts, M. C., Sprecher, S., \& Beck, F. D. (2004). Overview of sexual practices and attitudes within relational contexts. In J. H. Harvey, A. Wenzel, \& S. Sprecher (Eds.), The Handbook of Sexuality in Close Relationships (pp. 57-85) Mahwah, NJ, US: Lawrence Erlbaum Associates Publishers.

Yule, M. A., Brotto, L. A., \& Gorzalka, B. B. (2015). A validated measure of no sexual attraction: The asexuality identification scale. Psychological Assessment, 27, 148-160. doi:10.1037/a0038196

Yule, M. A., Brotto, L. A., \& Gorzalka, B. B. (2017). Sexual fantasies and masturbation among asexual individuals: An in-depth exploration. Archives of Sexual Behavior, 46, 311-328. doi:10.1007/s10508-016-0870-8 


\section{APPENDIX A: DEMOGRAPHICS QUESTIONNAIRE}

1. What is your current age?

- Fill in the blank

2. What is your biological sex?

- Male, Female, Intersex, Other (Please specify), Prefer not to answer

3. What is your gender?

- Man, Woman, Transgender, Non-Binary, Genderfluid, Other (Please specify), Prefer not to answer

4. What is your race/ethnicity?

- White/European American, Black/African American, Hispanic/Latinx, Asian/Pacific

Islander, Native American, Multi-Racial/Multi-Ethnic, Other (Please specify)

5. What is your current relationship status? Select all that apply.

- Single, Dating casually, Dating seriously, Living with partner, Open relationship, Engaged, Married, Divorced, Separated, Widowed, Other (please specify)

6. Do your currently have any children? Select all that apply.

- Yes (Biological), Yes (Adopted), Yes (Foster), No

7. With respect to romantic orientation, how do you self-identify? (As in, who are you romantically attracted to?)

- Heteroromantic, Homoromantic (Gay), Homoromantic (Lesbian), Bi-romantic, Panromantic, Aromantic, Other (Please specify), Prefer not to answer 8. With respect to sexual orientation, how do you self-identify? (As in, who are you physically attracted to?) 
- Heterosexual, Homosexual (Gay), Homosexual (Lesbian) Bi-sexual, Pansexual, Asexual, Asexual (Grey-A), Asexual (Demi-sexual), Asexual (A-Fluid), Other (Please specify) 9. Have you previously been in a romantic relationship?

- If yes: How old were you when you entered your first romantic relationship? (fill in the blank)

- If yes: For asexual participants only: What motivated you to engage in a romantic relationship? e.g. companionship, loneliness, societal/family expectations, etc. (fill in the blank)

- If no: Why have you not engaged in a romantic relationship? (fill in the blank)

10. Are you currently in a romantic relationship?

- If yes: How long have you been in your current romantic relationship? (fill in the blank)

- If yes: How would you categorize your current relationship? (Casually dating, Dating (exclusively), Engaged, Married, Other (Please specify))

- If yes: Other than yourself, how many partners are engaged in your current romantic relationship? (i.e., are you in a polyamorous or open relationship?) (fill in the blank)

- If no: Would you like to be in a romantic relationship either now or in the future? Why or why not? (fill in the blank)

11. Have you previously engaged in any consensual sexual experiences?

- If yes: How old were you when you first engaged in a sexual experience?

- If yes: For asexual people only: If you have engaged in sexual experiences, what motivated you? e.g. companionship, loneliness, societal/partner expectations, etc. (fill in the blank)

- If no: Why have you not engaged in any sexual experiences? (fill in the blank) 
12. What sexual orientation (if you could choose) would you prefer your romantic partner (current or hypothetical) to be?

- Heterosexual, Homosexual, Bi-sexual, Pansexual, Asexual, Not looking for a partner, No preference, Other (Please specify)

13. What sexual orientation (if you could choose) would you prefer yourself to be?

- Heterosexual, Homosexual, Bi-sexual, Pansexual, Asexual, No preference, Other (fill in the blank)

14. Would you be willing to be in an open or polyamorous relationship? As in, a non-exclusive relationship or one with multiple partners?

- Yes, No, Maybe, Not looking for a partner, No preference 


\section{APPENDIX B: PHYSICAL INTIMACY EXPERIENCE SCALE}

For each of the 22 items below, please rate how often you have previously engaged in the behavior while in a romantic relationship. If you have never been in a romantic relationship, please use your general experience overall. Use the scale from 1 ("never") to 5 ("a lot").

1. Holding hands:

$\begin{array}{ccccc}1 & 2 & 3 & 4 & 5 \\ \text { Never } & \text { Seldom } & \text { Sometimes } & \text { Often } & \text { A Lot }\end{array}$

2. Hugging:

$\begin{array}{ccccc}1 & 2 & 3 & 4 & 5 \\ \text { Never } & \text { Seldom } & \text { Sometimes } & \text { Often } & \text { A Lot }\end{array}$

3. Cuddling:

$\begin{array}{ccccc}1 & 2 & 3 & 4 & 5 \\ \text { Never } & \text { Seldom } & \text { Sometimes } & \text { Often } & \text { A Lot } \\ \text { ressing: } & & & & \\ 1 & 2 & 3 & 4 & 5 \\ \text { Never } & \text { Seldom } & \text { Sometimes } & \text { Often } & \text { A Lot }\end{array}$

5. Massaging (above clothes):

\section{1}

Never

2

Seldom

6. Massaging (under clothes):

1

Never
2

Seldom
3

Sometimes
4

Often
5

A Lot

7. Fondling (above clothes):

1

Never
2

Seldom
3

Sometimes
4

Often
5

A Lot
5

Often A Lot 
8. Fondling (below clothes):

$\begin{array}{ccccc}1 & 2 & 3 & 4 & 5 \\ \text { Never } & \text { Seldom } & \text { Sometimes } & \text { Often } & \text { A Lot }\end{array}$

9. Sharing a bed:

$\begin{array}{ccccc}1 & 2 & 3 & 4 & 5 \\ \text { Never } & \text { Seldom } & \text { Sometimes } & \text { Often } & \text { A Lot }\end{array}$

10. Kissing on the lips:

$\begin{array}{ccccc}1 & 2 & 3 & 4 & 5 \\ \text { Never } & \text { Seldom } & \text { Sometimes } & \text { Often } & \text { A Lot }\end{array}$

11. Kissing above the neck:

$\begin{array}{ccccc}1 & 2 & 3 & 4 & 5 \\ \text { Never } & \text { Seldom } & \text { Sometimes } & \text { Often } & \text { A Lot }\end{array}$

12. Kissing below the neck (Excluding genitals):

$\begin{array}{ccccc}1 & 2 & 3 & 4 & 5 \\ \text { Never } & \text { Seldom } & \text { Sometimes } & \text { Often } & \text { A Lot } \\ 1 & 2 & 3 & 4 & 5\end{array}$

13. French-kissing:

$\begin{array}{ccccc}1 & 2 & 3 & 4 & 5 \\ \text { Never } & \text { Seldom } & \text { Sometimes } & \text { Often } & \text { A Lot }\end{array}$

14. Making out:

$\begin{array}{ccccc}1 & 2 & 3 & 4 & 5 \\ \text { Never } & \text { Seldom } & \text { Sometimes } & \text { Often } & \text { A Lot }\end{array}$

15. Humping:

$\begin{array}{ccccc}1 & 2 & 3 & 4 & 5 \\ \text { Never } & \text { Seldom } & \text { Sometimes } & \text { Often } & \text { A Lot }\end{array}$


16. Foreplay:

$\begin{array}{ccccc}1 & 2 & 3 & 4 & 5 \\ \text { Never } & \text { Seldom } & \text { Sometimes } & \text { Often } & \text { A Lot }\end{array}$

17. Bodily contact/touching (Nipples/breasts):

$\begin{array}{ccccc}1 & 2 & 3 & 4 & 5 \\ \text { Never } & \text { Seldom } & \text { Sometimes } & \text { Often } & \text { A Lot }\end{array}$

18. Bodily contact/touching (Genitals):

$\begin{array}{ccccc}1 & 2 & 3 & 4 & 5 \\ \text { Never } & \text { Seldom } & \text { Sometimes } & \text { Often } & \text { A Lot }\end{array}$

19. Genital touching (Orally):

$\begin{array}{ccccc}1 & 2 & 3 & 4 & 5 \\ \text { Never } & \text { Seldom } & \text { Sometimes } & \text { Often } & \text { A Lot }\end{array}$

20. Genital/genital contact (Including intercourse):

$\begin{array}{ccccc}1 & 2 & 3 & 4 & 5 \\ \text { Never } & \text { Seldom } & \text { Sometimes } & \text { Often } & \text { A Lot }\end{array}$

21. Anal touching (Including Orally):

$\begin{array}{ccccc}1 & 2 & 3 & 4 & 5 \\ \text { Never } & \text { Seldom } & \text { Sometimes } & \text { Often } & \text { A Lot }\end{array}$

22. Anal/genital contact (Including intercourse):

$\begin{array}{ccccc}1 & 2 & 3 & 4 & 5 \\ \text { Never } & \text { Seldom } & \text { Sometimes } & \text { Often } & \text { A Lot }\end{array}$




\section{APPENDIX C: INTIMATE BEHAVIOR ATTITUDE SCALE}

For each of the 22 items below, please rate how intimate you believe the behavior to be if performed in the context of a romantic relationship. Use the scale from 1 ("not intimate") to 5 ("very intimate").

1. Holding hands:

1

Not Intimate

2. Hugging:

1

Not Intimate

3. Cuddling:

1

Not Intimate

4. Caressing:

1

Not Intimate

5. Massaging (above clothes):

1

2

Not Intimate

6. Massaging (under clothes):

1

2

Not Intimate

7. Fondling (above clothes):

1

2

Not Intimate

8. Fondling (below clothes):

1

2
3

4

5

Very Intimate

3

4

5

Very Intimate

3

4

5

Very Intimate

3

4

5

Very Intimate

3

4

5

Very Intimate

3

4

5

Very Intimate

3

4

5

Very Intimate 
9. Sharing a bed:

12

Not Intimate

10. Kissing on the lips:

1

2

Not Intimate

11. Kissing above the neck:

1

2

Not Intimate

12. Kissing below the neck (Excluding genitals):
1

Not Intimate

13. French-kissing:
2

Not Intimate

14. Making out:

1

2

Not Intimate

15. Humping:

1

2

Not Intimate

16. Foreplay:

1

2

Not Intimate
3

3

3

4

5

Very Intimate

4

5

Very Intimate

4

5

Very Intimate

4

5

Very Intimate

4

5

Very Intimate

4

5

Very Intimate

4

5

Very Intimate

4

5

Very Intimate 
17. Bodily contact/touching (Nipples/breasts):

123

Not Intimate

18. Bodily contact/touching (Genitals):

1

2

Not Intimate

19. Genital touching (Orally):

1 2

Not Intimate

20. Genital/genital contact (Including intercourse):

1

2

Not Intimate

21. Anal touching (Including orally):

1

Not Intimate

22. Anal/genital contact (Including intercourse):

1

2

Not Intimate
3

3

3

4

5

Very Intimate

4

5

Very Intimate

4

5

Very Intimate

4

5

Very Intimate

3

4

5

Very Intimate

4

5

Very Intimate 


\section{APPENDIX D: SEXUAL BEHAVIOR ATTITUDE SCALE}

For each of the 22 items below, please rate how sexual or non-sexual you would consider the behavior to be if performed in a romantic relationship. Use the scale from 1 ("not sexual") to 5 ("very sexual").

1. Holding hands:

12

Not Sexual

2. Hugging:

1

Not Sexual

3. Cuddling:

1

Not Sexual

4. Caressing:

1

2

Not Sexual

5. Massaging (above clothes):

1

2

Not Sexual

6. Massaging (under clothes):

1

2

Not Sexual

7. Fondling (above clothes):

1

2

Not Sexual
3

4

5

Very Sexual

3

4

5

Very Sexual

4

5

Very Sexual

3

4

5

Very Sexual

3

4

5

Very Sexual

3

4

5

Very Sexual

3

4

5

Very Sexual 
8. Fondling (below clothes):

12

Not Sexual

9. Sharing a bed:

12

Not Sexual

10. Kissing on the lips:

1

2

Not Sexual

11. Kissing above the neck:

1

2

Not Sexual

12. Kissing below the neck (Excluding genitals):

1

2

Not Sexual

13. French-kissing:

1

Not Sexual

14. Making out:

1

2

Not Sexual

15. Humping:

1

2

Not Sexual
3

3

3

4

5

Very Sexual

4

5

Very Sexual

4

5

Very Sexual

4

5

Very Sexual

4

5

Very Sexual

4

5

Very Sexual

4

5

Very Sexual

4

5

Very Sexual 
16. Foreplay:
1
2

3

Not Sexual

17. Bodily contact/touching (Nipples/breasts):

1

Not Sexual

18. Bodily contact/touching (Genitals):

1

2

3

Not Sexual

19. Genital touching (Orally):

1

2

3

Not Sexual

20. Genital/genital contact (Including intercourse):
1

2

Not Sexual
3

4

5

Very Sexual

4

5

Very Sexual

4

5

Very Sexual

4

5

Very Sexual

21. Anal touching (Including orally):

1

2

Not Sexual

22. Anal/genital contact (Including intercourse):

1

2

3

Not Sexual
3

3

(1)

4

Very Sexual

5 


\section{APPENDIX E: FUTURE PHYSICAL INTIMACY SCALE}

For each of the 22 items below, please rate how likely it is that you would perform the behavior in the future, in the context of a current or hypothetical romantic relationship. Use the scale from 1 ("not at all likely") to 5 (“extremely likely”).

1. Holding hands:

12

Not at all likely

2. Hugging:

1

Not at all likely

3. Cuddling:

1

Not at all likely

4. Caressing:

1

2

Not at all likely

5. Massaging (above clothes):

1

2

Not at all likely

6. Massaging (under clothes):

1

2

Not at all likely

7. Fondling (above clothes):

1

2

Not at all likely
3

3

4

5

Extremely likely

4

5

Extremely likely

4

5

Extremely likely

4

5

Extremely likely

4

5

Extremely likely

3

4

5

Extremely likely

4

5

Extremely likely 
8. Fondling (below clothes):

1

2

Not at all likely

9. Sharing a bed:

1

2

3

Not at all likely

10. Kissing on the lips:

1

2

3

Not at all likely

11. Kissing above the neck:

1

2

3

Not at all likely

12. Kissing below the neck:

1

2

3

Not at all likely

13. French-kissing:

1

2

3

Not at all likely

14. Making out:

1

2

3

Not at all likely

15. Humping:

1

2

3

Not at all likely
4

5

4

5

4

Extremely likely

4

Extremely likely

Extremely likely

Extremely likely

4

5

Extremely likely

4

5

Extremely likely

4

5

Extremely likely

4

5

Extremely likely

16. Foreplay: 
1

Not at all likely

17. Bodily contact/touching (Nipples/breasts):

1

2

3

Not at all likely

18. Bodily contact/touching (Genitals):

1

2

3

Not at all likely

19. Genital touching:

1

2

3

Not at all likely

20. Genital/genital contact (Including intercourse):

1

2

3

Not at all likely

21. Anal touching:

1

2

3

Not at all likely

22. Anal/genital contact (Including intercourse):

1

2

3

Not at all likely
4

5

4

Extremely likely

4

5

Extremely likely

Extremely likely

5

Extremely likely

4

5

Extremely likely

4

5

Extremely likely

4

5

Extremely likely 


\section{APPENDIX F: ENGAGEMENT IN SEXUAL INTIMACY ATTITUDE SCALE}

For each of the following 6 scales, how would you label your attitude or feelings about engaging in sexual intimacy?

1. 0

100

Negative

Positive

2. 0

100

Disgusted

Pleased

3. 0

100

Uninterested

Interested

4. 0

100

Not Aroused

Aroused

5. 0

100

Averse

Not Averse

6. 0

100

Unwilling

Willing

\section{Additional question:}

1. What is your general attitude about engaging in sexual intercourse?

-Positive, Neutral, Averse, None of these apply to me 


\section{APPENDIX G: ROMANTIC PARTNER LABEL QUESTIONNAIRE}

Instructions: Thinking about your current romantic partner(s), which words from the list below would you feel comfortable using to describe that person(s) or introduce this person(s) in various social situations? For example, you may use a different term to introduce this person(s) to your parent versus your friend. If you do not have a current partner, think about a past partner or a hypothetical future partner. You may choose all that apply.

- Crush

- Best Friend

- Girlfriend/Boyfriend

- Date

- Datemate

- Person

- Other Half

- Better Half

- Significant Other

- Companion

- Lover

- Soulmate

- Partner

- Life Partner

- Romantic Partner

- Fiancé

- Spouse

- Husband/Wife

- Other (Fill in the blank) 


\section{APPENDIX H: SOCIAL MEDIA RECRUITMENT TEXT TARGETING ASEXUAL PARTICIPANTS}

I am master's student at Illinois State University and I am conducting a survey regarding asexual people's attitudes to and experiences of romantic partner relationships. I am inviting your participation, which involves filling out an online questionnaire. Participation in the task will take approximately $\mathbf{1 5}$ minutes. Note that you do not have to identify as asexual to participate in this study. I am interested in the opinions of people of all sexualities (asexual, heterosexual, homosexual, bisexual, pansexual, etc.). The only requirement for participation is that you must be at least 18 years of age. Upon completion of the survey you will have the opportunity to be entered into a raffle for a \$20 Amazon.com gift card. If you would like to take the survey, please follow this link:

\section{LINK HERE}

You will be directed to a consent form. If you consent, you will be directed to the survey. 


\section{APPENDIX I: SOCIAL MEDIA RECRUITMENT TEXT FOR GENERAL RECRUITMENT}

I am master's student at Illinois State University and I am conducting a survey regarding people's attitudes to and experiences of romantic partner relationships. I am inviting your participation, which involves filling out an online questionnaire. Participation in the task will take approximately $\mathbf{1 5}$ minutes.

Note that you do not have to identify as a specific sexual orientation in order to participate in this study. I am interested in the opinions of people of all sexualities (asexual, heterosexual, homosexual, bisexual,

pansexual, etc.). The only requirement for participation is that you must be at least 18 years of age. Upon completion of the survey you will have the opportunity to be entered into a raffle for a $\$ 20$ Amazon.com gift card.

If you would like to take the survey, please follow this link:

\section{LINK HERE}

You will be directed to a consent form. If you consent, you will be directed to the survey. 